UNIVERSIDADE DE SÃO PAULO

ESCOLA DE ENFERMAGEM DE RIBEIRÃO PRETO

ENFERMAGEM EM SAÚDE PÚBLICA

RAQUEL ROSALVA GATTI

PREVALÊNCIA DE EXCESSO DE PESO EM ADOLESCENTES DE ESCOLAS PÚBLICAS E PRIVADAS DA CIDADE DE GUARAPUAVA-PR

Ribeirão Preto

2005 
UNIVERSIDADE DE SÃO PAULO

ESCOLA DE ENFERMAGEM DE RIBEIRÃO PRETO

\title{
PREVALÊNCIA DE EXCESSO DE PESO EM ADOLESCENTES DE ESCOLAS PÚBLICAS E PRIVADAS DA CIDADE DE GUARAPUAVA-PR
}

\begin{abstract}
Autora: Raquel Rosalva Gatti
Dissertação apresentada à Escola de Enfermagem de Ribeirão Preto no Programa de Pós-Graduação Enfermagem em Saúde Pública convênio MINTER realizado entre a Universidade de São Paulo e a Universidade Estadual do Centro-Oeste do Paraná. Inserido na linha de pesquisa: Assistência à criança e ao adolescente.
\end{abstract}

Orientadora:

Prof $^{\mathrm{a}}$ Dr $^{\mathrm{a}}$ Rosane Pilot Pessa Ribeiro

\section{Ribeirão Preto}


AUTORIZO A REPRODUÇÃO E DIVULGAÇÃO TOTAL OU PARCIAL DESTE TRABALHO POR QUALQUER MEIO CONVENCIONAL OU ELETRÔNICO, PARA FINS DE ESTUDO E PESQUISA. DESDE QUE CITADA A FONTE

\section{Catalogação na Publicação}

Serviço de Documentação de Enfermagem

Escola de Enfermagem de Ribeirão Preto

Universidade de São Paulo

GATTI, RAQUEL ROSALVA

Prevalência do excesso de peso em adolescentes de escolas públicas e privadas da cidade de Guarapuava - PR. Raquel Rosalva Gatti; orientador Rosane Pilot Pessa Ribeiro.

- Ribeirão Preto, 2005

84p

Dissertação (Mestrado - Programa de Pós Graduação em Enfermagem em Saúde Pública. Área de Concentração: Enfermagem em Saúde Pública. Linha de Pesquisa: Assistência a criança e ao adolescente Departamento de Enfermagem Materno Infantil e Saúde Pública - Escola de Enfermagem de Ribeirão Preto - Universidade de São Paulo.

1. Excesso de peso. 2. Adolescente. 3. Escolas. 
Data da defesa: 16/09/2005

Raquel Rosalva Gatti

\section{FOLHA DE APROVAÇÃO}

Prevalência de excesso de peso em adolescentes de escolas públicas e privadas da cidade de Guarapuava -PR.

Dissertação apresentada à Escola de Enfermagem de Ribeirão Preto da Universidade de São Paulo, para obtenção do título de Mestre em Enfermagem em Saúde Pública.

Área de Concentração: Assistência a criança e ao adolescente.

Aprovado em:

Comissão Julgadora

Profa. Dra. Rosane Pilot Pessa Ribeiro

Instituição: Assinatura:

Profa. Dra. Maria das Graças Bomfim Carvalho

Instituição: Assinatura:

Dra. Graziela Vieira Bassan dos Santos Instituição: Assinatura 


\section{DEDICATÓRIA}

Dedico este trabalho aos:

Meus filhos, Natália e Mateus

Dois adolescentes maravilhosos

Que são a razão da minha vida

Que são a minha vida

Amo vocês. 


\section{AGRADECIMENTOS}

Agradeço primeiramente a Deus, nosso Pai Maior, pela Fé de acreditar que os sonhos se conquistam com dedicação e determinação.

A minha amada mãe, que me ensinou desde pequena a dar valor as oportunidades de estudo e a valorizar este bem, como a melhor herança que os pais podem deixar aos filhos, pois o aprendizado ninguém nos rouba.

A minha família, Johnny, Nati e Mateus, por entender minhas ausências e minhas angústias, quero que saibam que esta conquista é nossa.

As diretoras das escolas pela permissão a mim concedida

Aos pais dos adolescentes pela autorização para realizar a pesquisa

Aos adolescentes pela colaboração

A minha companheira e orientadora Prof ${ }^{a}$ Rosane P.Pessa Ribeiro pela orientação imprescindível durante a elaboração e conclusão deste sonho.

As acadêmicas do Curso de Nutrição, durante a coleta de dados, sem a ajuda de todas eu certamente não teria chegado até aqui.

Aos professores do MINTER e aos meus colegas de mestrado e do departamento de Nutrição que caminharam comigo nessa jornada.

Minha gratidão à professora Cláudia Benedita dos Santos, por sua dedicação durante a análise dos resultados.

Muito obrigado à professora Zezé Bistafa pelo espaço em seu computador para trabalhar na digitação deste trabalho.

Agradeço aos membros da banca examinadora, $\operatorname{Prof}^{\mathrm{a}} \operatorname{Dr}^{\mathrm{a}}$ Graça e $\operatorname{Dr}^{\mathrm{a}}$ Graziela pelas recomendações sugeridas para apontar novos horizontes.

MEU SINCERO AGRADECIMENTO A TODOS!! 


\section{SUMÁRIO}

\section{RESUMO}

SUMMARY

ABSTRACT

1.INTRODUÇÃ O................................................................................................... 1

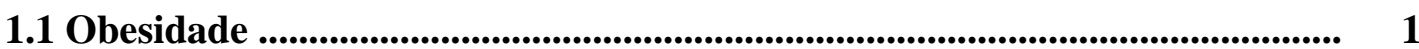

1.1.1 Definição e etiologia ................................................................................. 1

1.1.2 Prevalência.......................................................................................................... 7

1.2 Parâmetros para estimar o excesso de peso...................................................... 12

1 .3 Adolescência.................................................................................................. 20

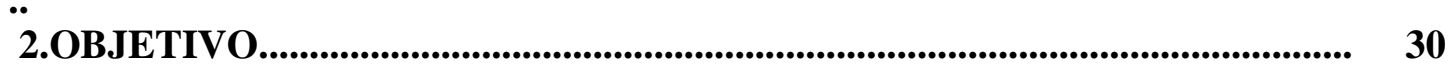

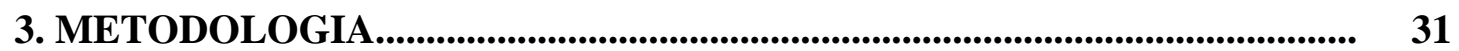

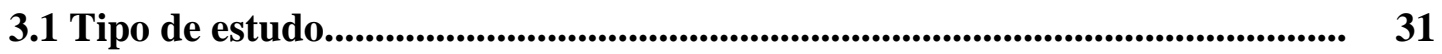

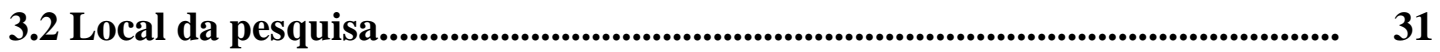

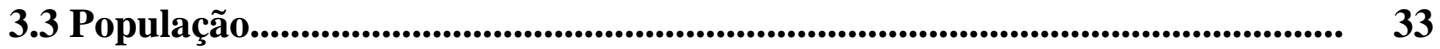

3.4 Procedimento amostral................................................................................................. 33

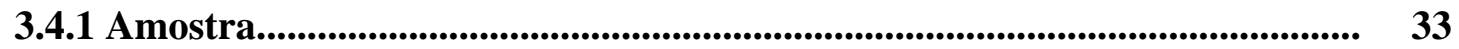

3.4.2 Sorteio da amostra.................................................................................................... 34

3.5 Coleta de dados........................................................................................................................... 35

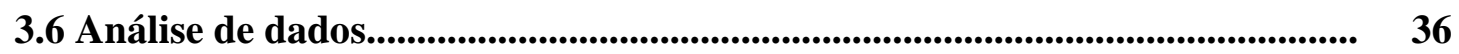

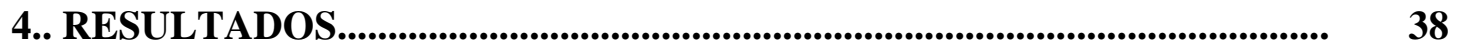

4.1 Características demográficas......................................................................................... 38

4.2 Características antropométricas.............................................................................. 41

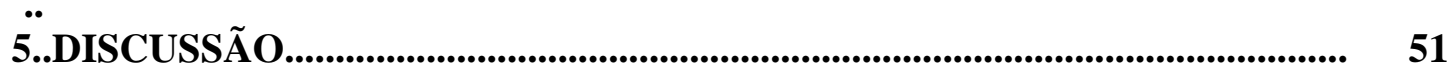




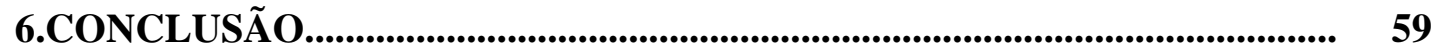

7.CONSIDERAÇÕES FINAIS.............................................................................. 60

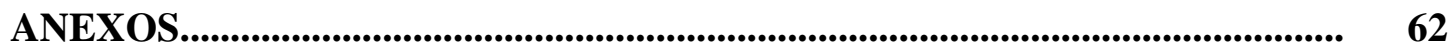

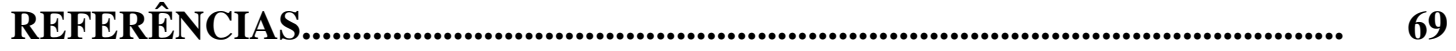




\section{LISTA DE ABREVIATURAS}

CDC - Centro de Controle e Prevenção de Doenças

DCV - Doenças Cardiovasculares

ECA - Estatuto da Criança e do Adolescente

GH -Growth Hormone - Hormônio do Crescimento

IBGE - Instituto Brasileiro de Geografia e Estatística

IMC - Índice de Massa Corporal

INAN - Instituto Nacional de Alimentação e Nutrição

MONICA - Monitoring of Trends and Determinantes in Cardiovascular Diseases

NHANES -National Health and Nutrition Examination Survey

NCHS- National Center for Health Statistics

OMS - Organização Mundial da Saúde

PNSN - Pesquisa Nacional sobre Saúde e Nutrição

POF - Pesquisa de Orçamentos Familiares 


\section{LISTA DE FIGURAS}

Figura 1 - Distribuição da amostra de acordo com o sexo e rede de ensino.

Guarapuava - PR, 2004.

Figura 2 - Distribuição da amostra de acordo com a idade e rede de ensino.

Guarapuava- PR, 2004.

Figura 3 - Histograma dos pesos dos alunos incluídos na amostra.Guarapuava PR, 2004.

Figura 4 - Histograma das alturas dos alunos incluídos na amostra. Guarapuava PR, 2004.

Figura 5 - Histograma dos Ïndices de Massa Corporal dos alunos incluídos na amostra.- Guarapuava - PR, 2004.

\section{LISTA DE QUADROS}

Quadro 1 - Valores de IMC segundo percentis 85 e 95 de acordo com sexo e idade.

Quadro 2 - População de alunos em escolas públicas - Guarapuava- PR, 2004 ......

Quadro 3 - População de alunos em escolas privadas - Guarapuava-PR, 2004 


\section{LISTA DE TABELAS}

Tabela 1- Distribuição da amostra conforme a idade e o sexo.Guarapuava-PR, 2004........................... 39

Tabela 2- Distribuição da amostra conforme a escola e a série. Guarapuava, PR, 2004.......................... 40

Tabela 3- Distribuição da amostra conforme a maturação sexual e a situação antropométrica Guarapuava -PR, 2004..

Tabela 4- Prevalência de sobrepeso da amostra conforme a idade e o sexo.Guarapuava -PR, 2004.

Tabela 5 - Prevalência de obesidade da amostra conforme a idade e o sexo. Guarapuava - PR, 2004.

Tabela 6 - Prevalência de sobrepeso da amostra conforme a escola. Guarapuava - PR,2004.

Tabela 7- Prevalência de sobrepeso da amostra conforme a série. Guarapuava - PR, 2004.

Tabela 8 - Prevalência de obesidade da amostra conforme a escola. Guarapuava - PR, 2004..

Tabela 9 - Prevalência de obesidade da amostra conforme a série. Guarapuava - PR, 2004..

Tabela 10 - Prevalência de sobrepeso da amostra conforme a maturação sexual. Guarapuava -PR, 2004.

Tabela 11- Prevalência de obesidade da amostra conforme a maturação sexual. Guarapuava-PR, 2004.

Tabela 12- Distribuição de alunos sorteados de escolas públicas segundo as séries sorteadas e segundo o gênero, 2004.

Tabela 13 - Distribuição de alunos sorteados de escolas privadas segundo as séries sorteadas e segundo o gênero, 2004. 


\section{RESUMO}

\section{GATTI, R.R. Prevalência de excesso de peso em adolescentes de escolas públicas e privadas da cidade de Guarapuava - PR. 2005. p.84}

Dissertação de Mestrado - Escola de Enfermagem de Ribeirão Preto, Universidade de São Paulo, Ribeirão Preto.

O excesso de peso é um grave problema de saúde pública na atualidade e vem sendo considerado uma epidemia nos países desenvolvidos. Este quadro predispõe os indivíduos a risco de desenvolvimento de doenças crônicas não-transmissíveis e quando instaladas na adolescência, são agravantes para perpetuação na idade adulta. O presente estudo teve como objetivo estimar a prevalência de excesso de peso em 386 adolescentes de ambos os sexos, com idade entre 10 e 14 anos, de duas escolas públicas e duas escolas privadas da cidade de Guarapuava-PR. A análise foi realizada com dados de peso e altura e cálculo do Índice de Massa Corporal, levando em consideração a idade, sexo, rede de ensino e a presença de maturação sexual. Como resultados, encontrou-se prevalência de sobrepeso de 13,0\% e obesidade de 3,4\% com níveis mais elevados em meninos do que em meninas. Praticamente a metade dos adolescentes apresentava sinais de maturação sexual e desses, 70,0\% tinham sobrepeso. Porém, naqueles com obesidade, a distribuição em relação à maturação sexual foi igual. Analisando-se pela origem da escola, os alunos da rede privada apresentaram índices mais elevados (16,2\% de sobrepeso e 3,8\% de obesidade) em relação aos da rede pública (10,0\% de sobrepeso e 3,0\% de obesidade). Concluiu-se que a alta prevalência de sobrepeso encontrada pode evoluir para obesidade justificando assim, a necessidade de políticas públicas que incentivem mudanças de hábitos de vida envolvendo a prática de atividade física e alimentação mais saudável.

Palavras-chave: adolescência, excesso de peso, escolas. 


\section{RESUMEN}

\section{GATTI, R.R. Prevalencia de exceso de peso en adolescentes de escuelas públicas y privadas de la ciudad de Guarapuava - PR. 2005. h.84}

Disertación de Maestría - Escuela de Enfermería de Ribeirão Preto, Universidad de São Paulo, Ribeirão Preto.

En la actualidad, el exceso de peso es un grave problema de salud pública y ha sido considerado como una epidemia en países desarrollados. Esta situación predispone a los individuos al riesgo de desarrollar enfermedades crónicas no transmisibles y, cuando instaladas en la adolescencia, son agravantes para perpetuación en la edad adulta. La finalidad de este estudio fue estimar la prevalencia del exceso de peso en 386 adolescentes de ambos sexos, con edad entre 10 y 14 años, de dos escuelas públicas y dos escuelas privadas de la ciudad de Guarapuava-PR. El análisis fue efectuado con datos de peso y altura y cálculo del Índice de Masa Corporal, considerando la edad, sexo, red de enseñanza y presencia de maduración sexual. Como resultados fueron encontrados tasas de prevalencia de sobrepeso de 13,0\% y obesidad de 3,4\% con niveles más elevados en chicos que en chicas. Prácticamente la mitad de los adolescentes presentaba señales de maduración sexual y, entre esos, 70,0\% manifestaban sobrepeso. Sin embargo, entre aquellos con obesidad, la distribución respecto a la maduración sexual fue igual. En el análisis según el origen de la escuela mostró que los alumnos de la red privada presentaban índices más elevados (16,2\% de sobrepeso y 3,8\% de obesidad) en comparación con aquellos de la red pública (10,0\% de sobrepeso y 3,0\% de obesidad). Concluimos que la alta prevalencia de sobrepeso encontrada puede evolucionar para obesidad, justificando así la necesidad de políticas públicas que estimulen cambios de hábitos de vida, involucrando la práctica de actividad física y alimentación más salubre.

Palabras-clave: adolescencia, exceso de peso, escuelas. 


\begin{abstract}
GATTI, R.R. Prevalence of overweight among adolescents at public and private schools in Guarapuava - PR. 2005. p.84

Masters Thesis - Ribeirão Preto College of Nursing, University of São Paulo, Ribeirão Preto.

Nowadays, overweight is a serious public health problem, which has been considered as an epidemic in developed countries. This situation predisposes individuals to the risk of non-transmissible chronic diseases which, when developed during adolescence, constitute aggravating circumstances for perpetuation into adulthood. This study aimed to estimate the prevalence of overweight in 386 male and female adolescents between 10 and 14 years old from two public and two private schools in Guarapuava-PR, Brazil. The analysis was based on weight, height and Body Mass Index data, considering age, gender, education network and sexual maturity. Prevalence rates amounted to $13.0 \%$ for overweight and 3.4\% for obesity, with higher levels among boys than among girls. Practically half of the adolescents displayed signs of sexual maturity, $70.0 \%$ of whom suffered from overweight. However, overweight students were equally distributed in terms of sexual maturity. As to the origin of the school, students from the private network presented higher levels (16.2\% for overweight and 3.8\% for obesity) in comparison with those from the public network (10.0\% overweight and $3.0 \%$ obesity). The high prevalence rates for overweight found in this study can evolve to obesity, which justifies the need for public policies that encourage changes in life habits involving physical exercise and healthier food habits.
\end{abstract}

Keywords: adolescence, overweight, schools. 


\section{INTRODUÇÃO}

\subsection{OBESIDADE}

\subsubsection{DEFINIÇÃO E ETIOLOGIA}

A obesidade, como problema de saúde pública assim como fator indutor de comportamentos individuais e sociais é de certa forma, algo moderno. Sua prevalência crescente reforça em nossos dias, toda uma popularização banalizada da própria obesidade (Sichieri, 1998) sendo atualmente configurada pela Organização Mundial da Saúde como uma epidemia global (WHO, 1997).

Esta organização chama a atenção para o fato de que a obesidade está aumentando mundialmente a uma taxa alarmante tanto nos países desenvolvidos quanto naqueles em desenvolvimento. Emitiu essa conclusão apesar da limitada disponibilidade de dados representativos em âmbito nacional e da falta de informações sobre tendências, alegando que a principal deficiência das análises de prevalência é devido à inexistência de pesquisas representativas sobre os países em desenvolvimento com renda elevada (WHO, 1997).

Considerando essa restrição, conclui-se que a obesidade parece não ser um problema de saúde pública entre a maioria dos países da Ásia e África. Todavia, em alguns países da América Latina e Caribe, África do Norte e Oriente Médio, e na região da Europa Oriental Central os níveis são tão elevados quanto nos Estados Unidos. Os índices de obesidade parecem estar crescendo na América Latina, mas a informação disponível é limitada (Martorell et al., 2000).

Ela é uma das enfermidades mais antigas do homem, pois já na pré-história, os desenhos mostravam o homem com aspectos de peso excessivo em relação a sua altura (Fisberg, 1995). 
Existem diferentes terminologias quanto à conceituação do excesso de gordura e de peso corporal. Sobrepeso é definido como um aumento excessivo de peso corporal total que excede um padrão baseado na altura enquanto a obesidade é um estado de adiposidade generalizada ou localizada no qual a gordura corpórea está acima do ideal (Santos, 2003).

As definições de excesso de peso e obesidade deveriam basear-se, idealmente em critérios de saúde, notadamente nas estatísticas de morbidez e mortalidade. Infelizmente, poucos dados encontram-se disponíveis a este respeito (Borges et al., 1998).

Abrahão, em 2002, conceituou a obesidade como o resultado do desequilíbrio permanente e prolongado entre a ingestão calórica e gasto energético onde o excesso de calorias se armazena como tecido gorduroso.

Um relatório divulgado em 2004 pelo Centro de Controle e Prevenção de Doenças (CDC) mostrou que, na última década, as mortes por obesidade aumentaram num ritmo quase quatro vezes maior do que as causadas pelo fumo (Folha de São Paulo, 2004).

Esse aumento da prevalência tem uma alta conexão com doenças crônicas nãotransmissíveis sendo estas, as maiores causas de mortalidade em muitos países (De Angelis, 2002).

O sobrepeso e a obesidade na infância e adolescência vêm sendo considerados graves problemas visto que a adolescência é um dos períodos críticos no desenvolvimento de maior acúmulo de gordura corporal, associando-se a este, complicações que decorrem deste estado, como o, diabetes do tipo II, doenças cardiovasculares e osteoporose (Dietz, 1994; OMS, 1995).

Além do excesso de peso ser fator de risco para o desenvolvimento de doenças crônicas, nível elevado de leptina e de ácido úrico tem sido observados em indivíduos obesos. O 
conjunto destas alterações tem sido descrito como "síndrome metabólica" ou "síndrome da resistência à insulina", já que a hipeinsulinemia tem um papel importante no desenvolvimento dos outros componentes da síndrome metabólica e comprovadamente estas alterações já estão presentes em crianças e adolescentes (Oliveira et al., 2004).

Estes mesmos autores relatam que a presença de pelo menos um fator de risco para doenças cardiovasculares (DCV), como hipertensão, dislipidemia ou hiperinsulinemia tem sido observada em $60 \%$ das crianças e dos adolescentes com excesso de peso, sendo que $20 \%$ apresentam dois ou mais fatores de risco. $\mathrm{O}$ índice de resistência à insulina é um forte preditor para a diminuição da tolerância à glicose, desenvolvendo mais rapidamente o diabetes tipo II na infância do que na fase no adulta. Com esta resistência, ocorrem alterações no perfil lipídico (dislipidemia), alteração da pressão arterial (indivíduos obesos hipertensos tem uma redução da sensibilidade à insulina), pois, adolescentes obesos têm um risco 2,4 vezes maior de desenvolver pressão arterial elevada do que os eutróficos, níveis elevados de ácido úrico (hiperuricemia) que estão relacionados também a resistência à insulina, maior nível de leptina (hormônio secretado pelos adipócitos que influenciam na diminuição da ingesta alimentar) devido a menor sensibilidade à insulina (relação indireta). Todos esses fatores em indivíduos obesos aumentam potencialmente os riscos para o desenvolvimento das doenças cardiovasculares na vida futura, e assim maiores taxas de morbi - mortalidade.

O peso excessivo em meninas e meninos na puberdade causa problemas psicológicos que afetam as atividades sociais, educacionais, esportivos e também se torna um fator de predisposição para doenças crônicas não transmissíveis (Rosenbaum, 1989; Must et al.; 1992).

Gortmaker et al., (1995) concluíram, após estudos com pacientes obesos durante um acompanhamento de sete anos, que esta condição teve um impacto negativo tanto social quanto econômico, muito superior ao da maioria de outras doenças crônicas. 
A obesidade tem causas multifatoriais, dentre elas o sedentarismo, consumo excessivo de calorias versus gasto energético reduzido, hábitos alimentares inadequados, alterações neuroendócrinas, meio ambiente, e estrutura familiar cada vez mais permissiva à expressão das tendências genéticas da obesidade (Coutinho, 1998).

Fatores primordiais na gênese da obesidade são os genéticos, os fisiológicos e os metabólicos, no entanto, os mais preponderantes parecem estar mais relacionados às mudanças no estilo de vida e aos hábitos alimentares, como o aumento no consumo de açúcares simples e gorduras, que possuem alta densidade energética e a diminuição da prática de atividade física, ou seja, fatores relacionados ao meio ambiente. Neste contexto, pode-se verificar que a prevalência crescente de obesidade infantil na adolescência é inversamente relacionada com a prática de atividade física sistemática, com mais horas de exposição ao hábito da TV, computador e videogame nas residências, associados ao baixo consumo de verduras e frutas, confirmando a influência do meio ambiente sobre o excesso de peso no nosso meio (Oliveira; Fisberg, 2003).

A facilidade na obtenção de alimentos ricos em gorduras e açucares simples, e o aumento do avanço tecnológico estão totalmente relacionados com o aumento da prevalência da obesidade, além da contribuição dada pelo aumento das porções dos alimentos servidos em restaurantes como descritos nos estudos de Young e Nestlé, que demonstraram que as porções servidas ultrapassam absurdamente aquelas padronizadas pelo Departamento de Agricultura dos Estados Unidos da América (USDA). O aumento das porções iniciou-se a partir da década de 70, coincidindo com o fortalecimento do marketing na indústria alimentícia (Oliveira \& Fisberg, 2003).

Os hábitos alimentares familiares inadequados correspondem a grande causa da obesidade na adolescência que em muitos casos tiveram início na infância. 
A obesidade iniciada nestes períodos é mais grave do que aquela que surge na idade adulta, pois, decorre do aumento do número de células adiposas, ao contrário daquela do adulto, causada, sobretudo, pelo aumento do volume e conteúdo gorduroso celular (Nunes \& Abuchaim 1998).

Esta situação é uma síndrome complexa que desencadeia sérios riscos à saúde para os indivíduos. Sendo assim, merece abordagem terapêutica especializada e interdisciplinar, apesar das dificuldades na obtenção de resultados satisfatórios (Santos, 2003).

A obesidade pode ser classificada de acordo com a distribuição de gordura: gordura acumulada acima do umbigo chama-se de obesidade superior ou andróide, gordura que predomina abaixo do umbigo, ou seja, na metade inferior do corpo denominada ginóide.

Quando se classifica a obesidade deve-se levar em conta que ela é uma enfermidade heterogênea e multifatorial, variando sua etipatogenia, suas características anatomopatológicas, a apresentação e evolução do seu quadro clínico, assim como a concomitância ou não de fatores de risco para a saúde. Isso determina que seja classificada de várias formas, dependendo do fator a considerar, podendo ser: segundo o grau de obesidade pelo Índice de Massa Corporal (IMC), a distribuição de gordura (andróide ou abdominal, ginóide ou femoroglútea) ou generalizada, a idade de início (início na infância, adolescência ou na idade adulta). Também pode ser classificada etiologicamente por desequilíbrio nutricional, por inatividade física, por alterações neuroendócrinas, por drogas e cirurgias (Abrahão, 2002).

Segundo algumas autoras, existem três períodos críticos para o desenvolvimento da obesidade e de suas complicações, que são: durante a gestação e primeiro ano de vida, entre os cinco e sete anos de idade e na adolescência. Elas descrevem ainda que a obesidade desencadeada nesses períodos, especialmente no segundo se caracteriza pela sua persistência e complicações (Mello et al, 2004). 
Um peso excessivo que permaneça após a idade de 12 anos aumenta, substancialmente, as chances de obesidade na idade adulta (Fonseca et al., 1998).

Os fatores de natureza alimentar determinantes para estes quadros são: desmame precoce e introdução inadequada de alimentos de desmame, emprego e fórmulas lácteas preparadas inadequadamente, distúrbios do comportamento frente aos alimentos e hábito alimentar familiar prejudicado (Fisberg, 1995).

Sendo a obesidade de causa nutricional denominada exógena aquela que representa o tipo mais freqüente (mais de 95\% dos casos), a forma generalizada sem distribuição regional preferente é a mais comum na criança e no adolescente (Sigulem et al., 2001).

Do ponto de vista epidemiológico, tudo conduz às explicações para que o aumento do peso seja de etiologia ambiental, já que não acontecem alterações substanciais nas características genéticas da população (Sigulem et al., 2001).

A história familiar é muito importante para determinar a ocorrência da obesidade. Autores descrevem que crianças com pais obesos tem $80 \%$ de chance de apresentar o mesmo perfil e este reduz pela metade se só um dos pais é obeso. Se nenhum dos pais apresentarem obesidade, a criança tem risco de 7\% de vir a ser obeso (Garn et al., 1991; Halpern et al., 1995; Sigulem, 2001).

Por outro lado, a nutrição adequada para um crescimento e desenvolvimento correto, torna-se muitas vezes um problema obsessivo para muitos adolescentes, cuja maior consciência de sua aparência física causa insatisfação com o peso e a imagem física. Um relatório de Saúde do Jovem da América, realizado em 1989 mencionou que 61\% das meninas adolescentes e $28 \%$ dos meninos adolescentes se submetem a regimes excessivos com perda de peso inapropriada em meninas, geralmente interferindo no crescimento normal e nos ciclos menstruais. A maioria dessas adolescentes se submetem a regimes sem supervisão de profissionais da área da saúde. Esses regimes deficientes podem ser fatores que 
criam uma predisposição para distúrbios alimentares mais sérios, tais como anorexia nervosa e bulimia, com todas as seqüelas psicológicas, ginecológicas e metabólicas (US Dept of Health and Human Services, 1989).

\subsubsection{PREVALÊNCIA}

Estudo de prevalência é aquele em que, sem levar em conta os acontecimentos passados ou futuros, mede-se a suposta causa e respectivo efeito em dado momento ou lapso de tempo (Forattini,1976) e incidência é a taxa de aparecimento de casos novos numa população (Camara, 2004).

Em sua reunião anual/2002, a OMS revelou estimativa em torno de 300 milhões de pessoas em todo mundo consideradas obesas e outras 750 milhões que estão acima do peso ideal (Santos, 2003).

Esses números crescem assustadoramente e devido a este fato muitos especialistas estão concentrando seus estudos na tentativa de reverter esse quadro, procurando conscientizar a população na adoção de estilos de vida saudáveis, entre outras medidas profiláticas e terapêuticas.

Nos Estados Unidos, em torno de $60 \%$ dos adultos são obesos ou estão acima do peso ideal e $13 \%$ das crianças são obesas (Santos,2003). Outro estudo neste mesmo país realizada em 1991(National Health and Nutrition Examination Survey - NHANES) monstrou que 22\% da população adulta é obesa, definida pelo IMC maior que $27,8 \mathrm{Kg} / \mathrm{m}^{2}$ para homens e 27,3 $\mathrm{kg} / \mathrm{m}^{2}$ para mulheres. Além disso, $15 \%$ a $20 \%$ das crianças e adolescentes são obesos (Damiani,et al., 2000). 
$\mathrm{Na}$ década de 90, um em cada cinco adolescentes americanos tinha peso excessivo e dados de 1988-91 mostram aumento de 40\% da prevalência para esta faixa etária (US. Department of Health and Human Services, 1996).

De acordo com a OMS, a prevalência de obesidade tem crescido em torno de 10 a $40 \%$ na maioria dos países europeus nos últimos 10 anos, ressaltando que esta ocorre mais frequentemente no primeiro ano de vida, entre 5 e 6 anos, e na adolescência (Mello et al., 2004).

Resultados do estudo MONICA (Monitoring of Trends an Determinantes in Cardiovascular Diseases - 1993/86) mostraram aumento da prevalência de obesidade entre $10 \%$ e $40 \%$ na maioria dos países da Europa sendo que o maior aumento foi na Inglaterra onde a prevalência duplicou (WHO, 1997).

Em Portugal, investigação apontou prevalência de obesidade em jovens e adolescentes em torno de 19\%, aumentando no adulto para 56,3\% (Torres et al., 1990; Lima , 2000).

Verifica-se que o aumento da prevalência de obesidade na América Latina está claramente relacionado com o número de mortes por doença cardiovascular (Damiani et al., 2002).

As informações sobre as tendências da obesidade são limitadas a dados específicos de alguns países e o valor médio da prevalência desta em oito países analisados é de $8 \%$ a $10 \%$, levando-se em conta mulheres e crianças (Damiani et al., 2002).

Em nosso país, tornam-se cada vez mais presentes os diversos graus de obesidade, sendo que por outro lado, tem sido constatada a diminuição da subnutrição. Nas últimas décadas, dados mostravam que em 1975 tínhamos em torno de 8\% de subnutridos e mais ou menos a metade, $4 \%$, de obesos. Este quadro atualmente está invertido com $9 \%$ de obesidade e somente 3\% de subnutrição (Monteiro et al., 1995). 
Estudos recentes trouxeram informações sobre a obesidade em adolescentes que variam de 8 a $20 \%$ em diferentes locais geográficos. Dados sobre prevalência, tanto para sobrepeso quanto para obesidade na adolescência são escassos. Os poucos estudos revelam crescente aumento de obesidade no Brasil tanto em crianças, como em adolescentes além de adultos (Lamonier, 2000).

A Pesquisa de Orçamentos Familiares (POF) de 2002/03 realizada pelo Instituto Brasileiro de Geografia e Estatística (IBGE) em indivíduos adultos do país estimou cerca de $40 \%$ de excesso de peso, ou seja, IMC igual ou maior do que $25 \mathrm{Kg} / \mathrm{m}^{2}$, não havendo diferença percentual entre homens e mulheres. Entre homens, a prevalência de excesso de peso é maior nas Regiões Sudeste, Sul e Centro-Oeste e sempre maior nas áreas urbanas do que nas rurais. Entre as mulheres, a prevalência do excesso de peso difere menos entre as regiões e com exceção da Região Nordeste, é maior nas áreas rurais do que nas urbanas. Em relação à obesidade, caracterizada por IMC igual ou superior a $30 \mathrm{Kg} / \mathrm{m}^{2}$, esta afeta $8,9 \%$ dos homens e $13,1 \%$ das mulheres e a distribuição regional e econômica se aproxima da da observada pelo excesso de peso (IBGE, 2004).

No Brasil, pesquisas realizadas para diagnosticar o excesso de peso na infância e na adolescência empregando o IMC como critério avaliativo, trouxeram alguns resultados mostrando quadro de transição nutricional, ou seja, aumenta o número de obesos e diminui o número de subnutridos, modificando o panorama apresentado há uma década passada (Mello et al., 2004).

De acordo com um estudo de revisão sobre a abordagem terapêutica da obesidade infantil e aspectos de seu diagnóstico, as autoras demonstraram freqüência aumentada de obesidade e desnutrição em duas regiões do país em três décadas: em 1975 no Nordeste existia $8,9 \%$ desnutridos contra $1 \%$ de obesos, em $1989,4,9 \%$ desnutridos e $2,5 \%$ obesos, e 
em 1997, 5,9\% desnutridos e 4,6\% obesos. Já na região Sudeste, nestes mesmos anos obtiveram-se resultados de desnutrição e obesidade respectivamente: de $8,2 \%$ e $2,5 \% ; 3,9 \%$ e 7, 3\%; 5,3\% e 12,9\% observando-se com esses dados o fenômeno chamado de transição nutricional (Mello et al., 2004).

A evolução do perfil- antropométrico - nutricional da população adulta brasileira é caracterizada pela comparação de 2002/03 com estimativas de pesquisas anteriores realizadas no país em 1974/75 e em 1989. A POF observou que o excesso de peso e obesidade aumentam contínua e intensamente na população masculina: a prevalência de excesso de peso mais do que duplica entre a primeira e a terceira pesquisas, enquanto a de obesos mais do que triplica. A evolução de excesso de peso e obesidade nas mulheres é diferente nos dois períodos, demarcados pelas três pesquisas: aumento de cerca de 50\% entre 1974/75 e 1989 e estabilidade relativa entre 1989 e 2002/03 (IBGE, 2004).

Esse estudo mostrou que a obesidade está presente nas diferentes faixas econômicas, com maior prevalência nas regiões menos desenvolvidas e menor prevalência nas regiões mais desenvolvidas.

Segundo pesquisa realizada pela Força Tarefa Latino - Americana de Obesidade, o índice de crianças e adolescentes obesos aumentou 240\% no Brasil nos últimos 20 anos, com 70 milhões de pessoas acima do peso (Instituto de Endocrinologia E... 2004).

$\mathrm{Na}$ adolescência, amostras populacionais investigadas em algumas capitais confirmaram essa realidade. A prevalência total foi de 7,8\% em Belo Horizonte em 1993 e 8,5\% em 1998; 15,6\% em Curitiba em 1996; 12,2\% no Rio de Janeiro em 1999 e 22,3\% em Florianópolis no ano de 1999 (Lamonier, 2000).

Outra pesquisa realizada no Rio de Janeiro em 1994, envolvendo várias instituições de ensino e saúde, resultou em prevalência de obesidade em adolescentes de 12 a 18 anos na 
ordem de $15 \%$. O método utilizado para a classificação do excesso de peso neste estudo foi o IMC proposto por Sichieri e Allam (1996).

A discordância entre diferentes levantamentos para classificar a obesidade na adolescência dificulta a obtenção de uma visão geral sobre prevalência neste grupo etário. No

Brasil, os dados são poucos conhecidos no que se refere a estudos de base populacional (Lamonier, 2000).

Em pesquisa realizada em 2002, com adolescentes sadios de ambos os sexos, institucionalizados no Centro de Juventude do município de São Paulo, obteve prevalência de $22,1 \%$ de risco de sobrepeso e sobrepeso, além de 5,5\% de magreza/baixo peso (Ochsenhofer et al., 2004).

Em estudo com o objetivo de avaliar o estado nutricional de adolescentes, realizou-se uma pesquisa transversal em escola publica de ensino fundamental e médio no município de São Paulo, com alunos de $5^{\mathrm{a}}$ a $8^{\mathrm{a}}$ séries, com idades entre 11 e 17 anos, no ano de 1998. Com as variáveis peso e altura, utilizaram-se o cálculo do IMC para idade e sexo, de acordo com o percentil do IMC, recomendados pela OMS. Os resultados encontrados foram de "risco de sobrepeso" e "sobrepeso" para o sexo masculino de $27,9 \%$ e $4,6 \%$ e para o sexo feminino, fo $10,2 \%$ e $16,3 \%$ respectivamente. Demonstrou -se com estes resultados, que a prevalência desses quadros foi elevada em ambos os sexos e semelhantes àquelas encontradas na literatura (Albano \& Souza, 2001).

Outra pesquisa desenvolvida em Bragança Paulista -SP realizou diagnóstico pelo IMC encontrando prevalência de 7,3\% de sobrepeso e 3,5\% de obesidade com maior prevalência de sobrepeso e obesidade em adolescentes que possuíam pais obesos $26,0 \%$ enquanto a prevalência foi $9,2 \%$ naqueles que possuíam pais eutróficos (Ramos \& Barros, 2003). 
A Pesquisa Nacional de Saúde e Nutrição (PNSN, 1975) mostrou que a prevalência de sobrepeso em meninas moradoras na região Sul do País é maior do que meninas americanas avaliadas pelo NHANES ( National Health Examination Survey) (Monteiro et al., 1995)

No Brasil, mais propriamente na região Sudeste e Sul, a ocorrência de obesidade na população adolescente é maior que a ocorrência de desnutrição (Muller, 2002).

Descreve-se que em sociedades industrializadas, a obesidade é uma desordem crônica muito comum em crianças e adolescentes, sendo considerada um preditor relevante de obesidade na vida adulta, acarretando situação de risco e provavelmente aumento da mortalidade devido à associação desta com as doenças cardíacas e de alterações metabólicas onde este quadro certamente deve-se a fatores ambientais (Novaes et al., 2003).

Segundo a última pesquisa realizada pelo Instituto Brasileiro de Geografia e Estatística em 1996, havia 34 milhões de adolescentes na faixa etária de 10 a 19 anos, ou seja, um em cada cinco brasileiros é adolescente. Estimou-se que 25\% destes, são obesos (Muller, 2002).

A partir desses dados, observa-se que o Brasil é um exemplo de mosaico, ou seja, existe alta prevalência de situações carenciais como a anemia e hipovitaminose mas também, alta prevalência de obesidade, características essas das condições sociais que representa ampla desigualdade e exclusão social (Silva, 1998)

\subsection{PARÂMETROS PARA ESTIMAR O EXCESSO DE PESO}

As necessidades nutricionais durante a adolescência possuem maior relação com a idade fisiológica do que com a cronológica, sendo diretamente proporcionais à velocidade de crescimento e às mudanças de composição corporal. A maturação sexual traduz o momento de crescimento, sendo relevante sua avaliação, tanto para diagnóstico como prognóstico das condições relacionadas ao estado nutricional (Colli, 1986). 
É relatado que a análise dos aspectos relacionados ao estado nutricional dos adolescentes pela antropometria deve ser visto com cautela, pois são observados resultados contraditórios quando utilizados diferentes processos de avaliação (Sichieri, 1998).

Estudos recentes demonstram que a análise de índices antropométricos isoladamente pode não ser suficiente para a avaliação de adolescentes com elevado grau de obesidade, havendo necessidade de associação de índices que possibilitem análises contínuas, com elevado poder de sensibilidade (Cintra et al., 2004).

Existem vários métodos para avaliar a composição corporal, todos eles indiretos, possuindo assim, limitações. São eles: 1) antropometria: apresenta facilidade na obtenção dos dados, necessitando apenas de pessoal treinado; 2) bioimpedância elétrica: sua precisão é questionável e é necessário equipamento de valor elevado; 3) análise de ativação de nêutron: método caro e limitado, devido à exposição à radiação; 4) potássio corporal total: no indivíduo adulto, o conhecimento do potássio corporal total permite estimativa da massa livre de gordura, no entanto, as constantes a serem utilizadas devem ser ajustadas para a idade e o sexo; 5) hidrometria: superestima a água corporal total; 6) absorciometria: há limitação devido à exposição à radiação; 7) técnicas de imagem: utilizam tomografia computadorizada, ressonância magnética e ultra-sonografia cujos métodos são de elevado custo (Cintra et al., 2004).

Entre outros métodos antropométricos para avaliar o estado nutricional está também o perímetro que avalia a massa muscular através da circunferência do braço e as dobras cutâneas possuindo limitações quanto ao custo e inaplicáveis em estudos populacionais (Cintra et al., 2004).

Atualmente, a literatura disponibiliza vários referenciais de curvas de crescimento aceitáveis no meio científico. Em 2004 Bueno e Mello, realizaram revisão bibliográfica e analisaram criticamente as curvas de crescimento usadas no momento. Nesta revisão, é 
contextualizado que o estado nutricional da criança e do adolescente reflete o seu crescimento e desenvolvimento tornando-se importante o acompanhamento destes grupos pelo peso e altura. Apesar de serem medidas antropométricas das mais utilizadas, para sua interpretação é necessário o uso de padrões de referência e de pontos de cortes definidos. (Bueno \& Mello, 2004).

O National Center of Health Statistics (NCHS), compilou curvas de percentis para avaliar o crescimento de indivíduos de 2 a 18 anos combinando três estudos transversais representativos nos Estados Unidos - National Health Examination Survey (NHES) Ciclo II para crianças de 6 a 11 anos e NHES Ciclo III para crianças de 12 a 17 anos e I National Health and Nutrition Examination Surves (NHANES) para crianças de 1 a 18 anos. Para o intervalo de 2 a 18 anos de idade foram produzidas curvas de percentis sexo-específicas similares de peso corporal para idade e estatura para idade. Desde 1978, a OMS reconheceu e recomendou o NCHS como adequado para diferentes grupos raciais para uso internacional sendo o mesmo adotado pelo Ministério da Saúde do Brasil (Bueno \& Mello, 2004).

O CDC iniciou uma revisão do NCHS, e no ano de 2000, um outro referencial foi publicado onde as novas curvas derivadas têm sido referidas como curvas de crescimento CDC/2000. As principais inovações para este referencial foram: aprimoramento das técnicas estatísticas, ampliação das amostras, padronização dos métodos de coleta de dados, extensão de todas as curvas até a idade de 20 anos, desenvolvimento do IMC por idade. Mesmo assim, uma das desvantagens das curvas do CDC é o fato destas incluírem dois novos estudos (NHANES Ciclo II e III) sendo que estes foram realizados na década de 80 e utilizaram crianças norte americanas. Como se sabe, há alta incidência de sobrepeso e obesidade nesta população, então, quando aplicadas em outras populações, essas curvas subestimam sobrepeso e obesidade classificando como desnutridas crianças com estado nutricional adequado. Desta forma, essas curvas não são recomendadas como referência pela OMS. Existem também as curvas de velocidade de crescimento que são usadas em estudos longitudinais, pois conforme 
a faixa etária está curva pode ser ascendente ou descendente determinando o estirão na infância e na adolescência (Bueno \& Mello, 2004).

A melhor maneira de avaliar o estado nutricional dos adolescentes e a progressão do seu crescimento é a utilização de medições cuidadosas que empreguem técnicas aprovadas e a comparação das medidas obtidas no decorrer do tempo com as normas apropriadas, levando em consideração também, a avaliação da maturidade sexual ou da idade óssea (Sigulem, et al, 2001).

Nesse sentido a antropometria é um método que utiliza as medidas de peso e altura, amplamente aceito, pois através dele realiza-se o cálculo para o IMC (Hammer, 1992).

O IMC é considerado uma medida de sobrepeso e não de obesidade, mas, a nível populacional uma alta prevalência de sobrepeso pode significar obesidade, pois a massa livre de gordura é pouco variável (Sichieri, 1998).

O IMC é um método seguro e bastante utilizado para avaliar o estado nutricional sendo que este é a proporção do peso do corpo para altura ao quadrado $\left(\mathrm{kg} / \mathrm{m}^{2}\right)$. Para calcular o IMC, o peso do corpo deve ser medido em quilogramas e a altura convertida de centímetros para metros $(\mathrm{cm} / 100)$. Ele foi considerado o parâmetro mais adequado para avaliação do estado nutricional de excesso de peso (Oliveira, 2002).

O uso do IMC por idade baseado no padrão internacional mostrou-se adequado para o diagnóstico de sobrepeso e obesidade na faixa etária da adolescência apresentando boa concordância com a adiposidade (Himes \& Dietz, 1994).

A utilização do IMC, como avaliação do excesso de peso, é validada devido à boa correlação que apresenta com a gordura corporal, principalmente com a gordura interna, sendo que esta se associa a fatores de risco para o surgimento de doenças crônicas (Anjos, 1992). 
O uso deste índice em adolescentes tem sido validado em muitos estudos, pois apresenta alta especificidade para diagnóstico da obesidade com ponto no percentil 95 (Nolasco, 1992: Mallina, 1999). Uma das limitações dele é que não reflete déficit na estatura, que é muito comum entre adolescentes de baixo nível socioeconômico (Priore, 1998).

Embora conhecidas suas limitações, deve-se considerar sua facilidade de mensuração, já que são utilizados dados antropométricos que são de fácil obtenção. Outra vantagem referese a sua boa reprodutibilidade (Garrow, 1985; Anjos, 1992).

O cálculo do IMC para identificar sobrepeso e obesidade em adolescentes são considerados atualmente como referência pela OMS, não sendo recomendados para crianças, que devem ser avaliadas com o índice de peso/altura (WHO, 1995).

Apesar de não haver dúvida quanto ao real aumento da obesidade na infância e adolescência, ainda existem dúvidas quanto ao melhor critério diagnóstico para essas faixas etárias. Segundo Fisberg, o P/E (peso por estatura) em crianças e o IMC em adolescentes seriam os melhores indicadores (Fisberg, 1995; WHO, 1995).

Para Bellizze et.al (1991) e Lamonier (2000) o excesso de peso na adolescência é caracterizado por um IMC/idade acima do percentil 85 como sobrepeso e obesidade acima do percentil 95, baseado também no NHANES II - III. Além disso, a adoção de padrões regionais também tem sido proposta.

Para os adolescentes, o valor $22 \mathrm{~kg} / \mathrm{m}^{2}$ do IMC com base nas análises da PNSNrealizada por Sichieri e Allam (1996), é o valor médio para ambos os sexos (para meninos é 21, e para meninas, 23). Sendo considerado ponto de corte para classificação de sobrepeso. Ressalta-se que para adolescentes não há consenso do valor mais adequado de normalidade.

Em 1995, a OMS recomendou o uso do IMC segundo valores definidos por Must et al (1991) obtidos de dados do NCHS, que foram corrigidos em outra publicação.Cole et al (2000) propuseram pontos de corte e curvas de IMC para faixa de 2 - 18 anos para uso 
internacional. Até o momento o que tem sido proposto é utilizar o IMC com os pontos de corte já estabelecidos para sobrepeso e obesidade na adolescência já que este índice tem sido validado contra medida de densidade corporal (Bellizzi et al., 1991).

$\mathrm{Na}$ criança e no adolescente, o IMC deve estar relacionado com a idade e o estágio de maturação sexual (Tanner, 1963; Gray, 1980; Mello et al., 2004).

Os valores de IMC levantados pela PNSN (Pesquisa Nacional sobre Saúde e Nutrição) realizada pelo INAN (Instituto Nacional de Alimentação e Nutrição) em 1989 demonstram que estes valores tendem a decrescer na faixa etária de 1 a 6 anos, mantêm-se estáveis até os 8 anos e aumentam progressivamente até se estabilizarem por volta de 19 a 20 anos para mulheres e 20 a 21 anos para homens. Esta mesma pesquisa também demonstrou que meninas apresentam valores de IMC superiores aos meninos a partir de 12 anos e também maiores diferenças nos percentis extremos, ou seja, de 3 a 97 (Brasil, 1990).

Comparando o IMC em jovens e crianças do Brasil com outros países, percebeu-se que estes valores são semelhantes aos norte- americanos até os 6 anos e inferior a partir dos 7 anos. Esses resultados podem ser utilizados para estudos de acompanhamento e comparação, mas é desaconselhável para monitoramento clínico, devido à variação individual ampla no desenvolvimento e crescimento durante a adolescência (Anjos et al., 1998).

Segundo Sichieri (1998) a utilização do IMC em países como o Brasil, onde as doenças infecciosas ainda têm um importante papel na morbidade, é questionável. Pode-se perguntar se é um indicador definido para os países em desenvolvimento, pois os estudos longitudinais concentram-se nos Estados Unidos e Europa, e deveriam ter o mesmo valor preditivo.

A dobra cutânea do tríceps e a circunferência braquial permitem avaliar, em seguida, relativamente aos padrões da população, o percentual de massa adiposa e massa magra do indi 
víduo. Estas medidas são simples, mas devem ser realizadas por pessoas treinadas, permitindo desta forma estimar confiavelmente a composição do organismo para que se possam acompanhar posteriormente, os efeitos do aconselhamento nutricional e dos tratamentos recomendados (Jacobson, 1998).

A avaliação da composição corporal e das variáveis antropométricas em adolescentes apresenta dificuldades, devido à ampla variação do tempo de início do estirão, pela variação da taxa de maturação e padrão de crescimento que está associado às diferenças étnicas entre os vários grupos existentes nas populações, além das distintas variações sócio-econômicas existentes.

Vários autores admitem que o número de técnicas para o estudo da composição corporal para crianças e adolescentes ainda são insuficientes quando comparadas aos adultos (Himes \& Dietz, 1994; Balabam, 2000).

Esse fato pode ser devido às imensas alterações na composição corporal que ocorrem nesta fase (puberdade, maturação sexual, porcentagem de gordura, músculos e ossos). Problemas de diagnóstico de excesso de peso nesta faixa etária decorrem da discordância quanto ao "ponto de corte" para sua identificação (Sampei et al., 2004)..

Garn et al em 1996 levantaram a interessante questão de que um peso saudável ou variações de peso têm necessariamente que estar associados ao desenvolvimento, ao sexo e as características que surgem em determinado momento da vida.

Diante dessa idéia para diagnóstico da obesidade na adolescência é necessário primeiramente avaliar o grau de maturidade sexual, verificando o estado do adolescente em relação ao estirão da puberdade, esperando que ele ocorra entre 12 e 14 anos para meninas e 14 e 16 anos para meninos (Almeida, 2000).

Percebe-se assim, que a avaliação antropométrica de adolescentes ainda é tema de grande polêmica, mas se sabe que é fundamental a avaliação da composição corporal com 
incorporação do estagiamento maturacional e sugere-se a utilização de pontos de corte a partir da distribuição do IMC na população (Roche,1981; Duarte, 1993; Himes,1994; Frederico et al., 1997).

Quantidade insuficiente de nutrientes retarda o início da puberdade, comprometendo o ganho estatural.Desta forma, acompanhar o crescimento e o desenvolvimento do adolescente é um instrumento fundamental para que se possa destinar ações para esse grupo (Root; Powers,1983).

Evidencia-se uma preocupação para estabelecer pontos de cortes para classificar o estado nutricional do adolescente, que é justificada em função do aumento da prevalência da obesidade no mundo todo e devido aos riscos potenciais para o desenvolvimento de doenças crônicas no adulto em função deste estado (WHO, 1995; Penã \& Bacallao, 2000)

Adolescentes têm uma grande variação de estatura durante esta fase influenciada por fatores genéticos e ambientais ( Brasil INAN-MS, 1990).

Grande número de jovens apresentam baixa estatura em países em desenvolvimento, provavelmente devido a graves problemas nutricionais na infância (Tanner, 1962). Desta forma utilizar valores de IMC obtidos de populações onde jovens atingiram seu potencial genético de crescimento pode levar a erros na avaliação nutricional, sendo necessário, estudo populacional sobre composição corporal associado à maturação sexual. Entretanto, são extremamente escassos estudos utilizando esta metodologia (Forbes \& King 1987; Duarte, 1993).

No caso do brasileiro, a estabilização de crescimento parece ocorrer aos 20 anos, sugerindo-se, portanto que esta é a idade mínima em que o IMC possa ser utilizado, lançando mão, dos limites de corte apontados para este índice (Satyanarayana \& Krishna, 1986; Anjos, 1994). 
Ao longo da adolescência, a composição corporal sofre imensas modificações e diferenciação entre meninas e meninos, assim, um mesmo IMC terá diferentes significados em termos de composição corporal dependendo do grau de maturação. Um fator limitante na literatura refere-se à falta de associação do IMC ao estagiamento da maturação sexual, que é a variável mais forte para o condicionamento do crescimento e desenvolvimento na adolescência. Ainda relata-se que existem variações individuais em relação aos eventos pubertários, dependendo do estágio de maturação onde se encontra o adolescente e o mesmo IMC, podem ter diagnósticos e prognósticos diferentes. Na conclusão de alguns estudos os autores sugerem que se garanta a associação da maturação sexual às medidas antropométricas (Anjos, 1998; Vitalle \& Amâncio, 1997).

\subsection{ADOLESCÊNCIA}

O termo "adolescência" foi introduzido na literatura científica em 1904, por Stanley Hall, apresentando uma visão global deste período da vida (Chipkevitch, 1995).

O primeiro tratado sobre a adolescência, foi publicado por Hall, em 1904, após um ano Jastrow, editou, “A história natural da Adolescência”. Com isso, os aspectos psicológicos dos adolescentes (Jastrow, 1905; Bridgman, 1918), bem como doenças primárias e secundárias associadas com a adolescência tornaram-se objeto de interesse crescente (Fuller, 1914; Mapes, 1917).

Segundo Chipkevitch (1995), referências a esta fase da vida, datam da Antigüidade egípcia e greco-romana, devido a suas características peculiares, mas, só mais tarde no século XX, a adolescência ficou reconhecida e estudada como um período específico do desenvolvimento humano. 
Amélia Gates trabalhou na primeira descrição para um departamento médico, com o tema especificamente devotado aos cuidados com adolescentes, onde ressaltou o quanto era importante para os médicos de adolescentes tratarem os males físicos, mas, também os problemas educacionais, sociológicos e psicológicos, deste período de transição (Dorfman, 1937).

Até 1927, muitos trabalhos e comunicações breves sobre a adolescência foram publicados abordando a obesidade na adolescência, a influência das glândulas endócrinas sobre o desenvolvimento muscular antes e após a puberdade, entre outros, e em 1930, o número de trabalhos aumentou para 45 onde eram abordados distúrbios de desenvolvimento e/ou problemas do crescimento enquanto outros se dedicavam aos aspectos psicológicos da adolescência (Heald, 1992).

Autores como Dorfam, Greulich e Salomon em 1937, publicaram dados importantes sobre a excreção urinária de substâncias androgênicas e estrogênicas por crianças e adolescentes, e estas observações demonstraram a grande variação dos níveis de esteróides e sua relação com o grau de desenvolvimento sexual dos adolescentes que serve de base à classificação das fases da puberdade de meninos e meninas (Heald, 1992).

No início da década de 40, a Academia Americana de Pediatria organizou dois simpósios sobre medicina dos adolescentes, e finalmente a primeira clínica geral para adolescentes foi fundada em 1952 por J. Roswell Gallagher, onde o primeiro programa de formação em medicina do adolescente foi iniciado (Gallagher, 1954).

De acordo com Ubeda (1996), nas últimas três décadas, a adolescência passou a ser vista de modo universal, onde as características de transformações físicas, psíquicas e sociais são evidentemente enormes e desta forma os adolescentes passam a merecer maior atenção no que se refere à saúde. 
Esta mesma autora (1996) considerou esta fase como um período de muitas mudanças, onde o jovem começa a se descobrir, a se perceber como único, com individualidade distinta, mas com características parecidas às dos outros jovens.

Entre 1950 e 1980, houve significativo aumento de adolescentes no mundo todo, e atualmente representam aproximadamente $30 \%$ da população. No Brasil, em 1980 cerca de 23\% da população era de adolescentes (Chipkevitch, 1995).

Em 1991, o Censo Demográfico/ IBGE revelou que 21,84\% eram habitantes na faixa etária de 10 a 19 anos, e desses 50,04\% eram do sexo masculino e 49,96 do sexo feminino. Ainda, $72,63 \%$ das pessoas de 10 a 14 anos e $74,3 \%$ das pessoas de 15 a 19 anos residem na área urbana (IBGE, 2004).

De acordo com a OMS (1989), ela compreende o período que vai dos 10 aos 19 anos, e assim merecem ser definidos: puberdade, juventude e adolescência. A faixa que vai dos 10 aos 14 anos é chamada de pré-adolescência ou adolescência precoce, adolescência é a faixa de 15 a 19 anos e juventude é a fase entre 19 e 24 anos de idade (Ramos et al.,2001; Abrantes, 2002).

O Estatuto da Criança e do Adolescente - ECA (1990), lei no. 8.069/90; no artigo 2º, considera adolescente para os efeitos da lei, a pessoa entre 12 e 18 anos de idade.

Quanto as Normas de Atenção à Saúde Integral do Adolescente do Ministério da Saúde (1993), a puberdade normal compreende o período de 8 a 16 anos de idade. E a puberdade precoce ocorre com o aparecimento de caracteres sexuais antes dos 8 anos de idade.

Aberastury e Knobel (1981) referem que em um contexto mais psicológico, é a etapa na qual o indivíduo busca a identidade adulta, apoiando-se nas primeiras relações afetivas, já interiorizadas, que teve com seus familiares e verificando a realidade que a sua sociedade lhe oferece. Esses mesmos autores revelam que o objetivo final do desenvolvimento do 
adolescente é a criação da própria identidade, que se processa através da interação do mundo interno com o externo.

A puberdade é caracterizada pelas modificações biológicas e morfológicas próprias dessa faixa etária e adolescência são as transformações biopsicossociais que as acompanham. Portanto a puberdade não tem sinonímia com adolescência, mas sim, é parte dela. Como etimologicamente o termo sugere, inicia-se com o crescimento dos pêlos em certas regiões do corpo, como nas axilas e região pubiana, em ambos os sexos, por ação hormonal desencadeada no período puberal. Do advento da puberdade ocorre à menarca ou primeira menstruação na menina, a primeira ejaculação no menino entre outras ocorrências próprias deste período (Osório, 1989; Leal \& Silva, 2001).

A pubescência (início da puberdade) é o período mais precoce da adolescência, onde ocorre um fenômeno biológico com a produção de androgênios pelos testículos e estrogênios e progesterona pelos ovários. Esses hormônios estimulam a maturação dos órgãos de reprodução e das características sexuais secundárias e estão associados ao hormônio de crescimento a somatotrofina ( Vitalle \& Amâncio, 1997; Leal \& Silva, 2001; Oliveira, 2004).

A adolescência inicia-se com a puberdade, que pode ser definida também com o começo da idade fértil. A puberdade é um fenômeno fisiológico ocorrendo tanto nas meninas como nos meninos, tornando-os aptos à função reprodutiva (Goldeberg et al., 1996).

Em ambos os sexos, a puberdade é caracterizada por uma hipertrofia e hiperplasia dos adipócitos, porém é significante a diferença na distribuição de gordura subcutânea de acordo com o sexo, com uma predominância de tecido adiposo na parte superior do corpo no sexo masculino e na parte inferior no feminino (Cintra et al., 2004).

Adolescentes da mesma idade podem estar em fases distintas da puberdade, pois esta tem início e ritmo de progressão variável entre eles. Adolescentes de mesmo peso, idade e 
estatura podem encontrar-se em momentos diferentes de seu crescimento e desenvolvimento de seus caracteres sexuais (Saito, 1993; Colli, 1993).

As meninas, em média, iniciam a puberdade mais cedo do que os meninos e sua velocidade máxima de crescimento em altura ocorrem, em média, mais precocemente no curso do seu desenvolvimento pubertário; no seu máximo esta velocidade, no entanto, é menor do que nos meninos. Nos dois sexos, a puberdade é acompanhada de um acréscimo de massa magra e massa adiposa. Todavia, se os meninos e meninas iniciarem o seu desenvolvimento pubertário com percentagens semelhantes de gordura e massa celular ativa, a massa adiposa representa, em geral, $25 \%$ do peso do corpo nas meninas na puberdade enquanto que só chega a constituir, em média 18\% nos meninos, que acumularam mais massa magra do que as meninas, tanto em valor absoluto como em relação ao seu peso. (Jacobson, 1998).

O desenvolvimento esquelético alcança maturidade no final da adolescência, o processo de crescimento da massa muscular total não é uniforme, desenvolve-se lentamente na infância e rapidamente na adolescência mais intensamente no sexo masculino do que no feminino. Quanto a estatura, na puberdade ela aumenta em torno de 5 a $6 \mathrm{~cm} / \mathrm{ano}$, sendo que o estirão de crescimento durante esta fase contribui com cerca de $15 \%$ da estatura, em média $50 \%$ do peso e em torno de $40 \%$ do conteúdo mineral total do adulto (Cintra et al., 2004).

Alguns autores mostraram que a secreção do hormônio do crescimento $(\mathrm{GH})$ aumenta durante a puberdade mais cedo nas meninas do que nos meninos. Este hormônio depende dos esteróides sexuais, e os dois são determinantes importantes do impulso de crescimento do adolescente. O GH desempenha um papel direto no estímulo do crescimento ósseo (Rose et al., 1988 ; Martha et al,. 1992).

As mudanças que se produzem durante a puberdade, segundo Sileo (1985), descrevem algumas características entre elas, a variação individual na idade de início do crescimento, 
pois as meninas iniciam este período um ano e meio a dois anos antes que os meninos e o processo de maturação podem durar de dois a cinco anos.

De acordo com Oliveira \& Fisberg (2003), o estirão pubertário tem duração media de três anos e começa mais cedo no sexo feminino, por volta de 9,5 anos, e no sexo masculino tem início dois anos mais tarde, aos 11, 5 anos, em média.

Esse período é marcado por profundas mudanças no que se refere aos aspectos biopsicossociais onde o adolescente começa a definir sua identidade, estabelecendo valores pessoais, ficando vulnerável aos agravos enfrentados pela maioria das sociedades atuais (Ministério da Saúde, 1993).

Winnicott (1993) nos coloca sabiamente que “(...) esta é uma fase que precisa ser efetivamente vivida, e é essencialmente uma fase de descoberta pessoal". Cada indivíduo vêse engajado numa experiência viva, num problema do existir.

O tamanho relativo da população juvenil cresce desta forma aumenta também a necessidade de informações sobre o desenvolvimento social e físico e sobre as políticas que podem afetar a sua saúde (Rodrigues ; Garcia et al., 1999).

$\mathrm{Na}$ adolescência, ocorrem mudanças em todas as esferas do ser humano, caracterizando-se como um dos períodos mais críticos do ciclo vital. Ocorre grande número de mudanças físicas, onde muitos padrões adultos são adquiridos (Guthrie et al., 1995; Bergada, 1998; Brasil, 1999). Desta forma, este momento é o mais oportuno para a prevenção de problemas de saúde do adulto.

Não se pode abordar o assunto adolescência sem discorrer sobre a questão da corporalidade, pois as modificações do corpo ocorrem de forma muito rápida, profunda e marcante para o resto de sua vida, podendo-se dizer que um corpo diferente de todos os outros emerge das profundezas desse turbulento processo, onde a identidade é talvez a tarefa evolutiva mais importante da adolescência. Devido às intensas modificações biológicas 
puberais, o adolescente passa a habitar um novo corpo. Este fenômeno pode ser vivido ansiosamente, transformando o corpo, ou seus órgãos, em um depositário de intensas ansiedades (Brêtas, 2003).

A maturação sexual é um processo que envolve o desenvolvimento das características sexuais primárias, que estão relacionadas diretamente com a reprodução. Muitos fatores estão associados ao processo de crescimento e maturação sexual. Em grande parte os fatores genéticos, são responsáveis pela variação individual dos fenômenos pubertários (Carrascosa \& Gussinyé, 1998).

Tanner e Marshall (1986) descrevem que no momento do estirão pubertário ocorrem alterações da composição corporal envolvendo esqueleto, músculos e modificações na quantidade e distribuição da gordura entre outras alterações. É nessa fase que o indivíduo adquire aproximadamente $50 \%$ de seu peso final e $20-25 \%$ de sua estatura definitiva (Vitalle \& Amâncio, 1997).

A composição corporal na adolescência se caracteriza por maiores depósitos de gordura em meninas e de músculos em meninos (Malina, 1978; Duarte, 1993).

É essencial compreender as modificações que ocorrem na composição da massa gorda e magra durante os períodos de crescimento, e dos componentes corporais a gordura é a mais vulnerável sofrendo maiores variações que podem ser de 10\% a 30\% (Cintra et al., 2004).

Quando se avalia o crescimento físico envolvendo o estado nutricional na adolescência além do peso e da estatura, deve-se considerar a maturação sexual que é representada pelo aparecimento dos caracteres sexuais secundários sendo que a idade cronológica na adolescência deixa de ser um parâmetro seguro (Kreipe, 1992).

A avaliação da maturação sexual, baseada nos caracteres sexuais secundários, apresenta dificuldades para sua realização devido a fatores culturais, necessidade de local apropriado e profissionais qualificados (Gambardella et al., 2004). 
Os estudos da maturação sexual concentram-se nas características sexuais secundárias (ligadas ao dimorfismo sexual externo) devido à impossibilidade de percepção visual das características sexuais primárias (desenvolvimento interno, de ovários, útero, vagina, testículos, próstata e outros órgãos da reprodução) (Duarte, 1993).

De acordo com Eckert (1993), o crescimento é um dos fatores que manifesta o surgimento da menarca.

No sexo feminino, a menarca tem sido muito utilizada, para avaliação da maturação sexual (Colli, 1985; Fonseca et al., 1998).

Para a ocorrência da menstruação é necessário que exista $17 \%$ da composição corporal de gordura e para a manutenção e regulação dos períodos ovolutórios, essa necessidade passa para $22 \%$ (Oliveira, 2002).

É importante salientar que a menarca é um fenômeno tardio dentro do processo pubertário, ocorrendo próximo ao seu fim, quando já está ocorrendo a desaceleração do crescimento ( Saito, 1993).

A idade da menarca é utilizada no Brasil, como indicador de maturação biológica das características sexuais femininas e com o advento dela, são notados nos indivíduos variações em desenvolvimento de massa corporal e estatura, sendo que muitos estudos demonstram que a adiposidade corporal tem um incremento significativo após a menarca. (Pozzobon, 2003).

Algumas pesquisas demonstraram que a porcentagem de gorduras em meninas que tinham experimentado a menarca há mais de dois anos foi de $30 \%$. Através destes estudos torna-se importante a preocupação com a alta prevalência de obesidade, pois se sabe que a adolescência pode ser um período importante no surgimento e perpetuação da obesidade no adulto (Sampei et al., 2004). 
Em pesquisa realizada em escola particular de São Paulo, foi encontrada tendência de aumento dos valores de hemoglobina sanguínea associada com o desenvolvimento sexual dos adolescentes (maturados) do sexo masculino e apontando maior prevalência de anemia somente para o sexo feminino, provavelmente devido à perda sanguínea causada pela ocorrência da menstruação (Juliano et al., 2004).

No que se refere ao sexo masculino é possível utilizar o surgimento dos pelos axilares para estadiamento da maturação sexual, já que este fato ocorre logo após o pico de velocidade em estatura, e pré-ocorrência do estágio final de maturação sexual (Duarte, 1993).

A elevação dos níveis de circulação de esteróides sexuais ocorre antes do aparecimento das características sexuais externas, sendo este fato de interesse porque algumas das atitudes comportamentais iniciais associadas com a puberdade, tais como alterações em atitudes, desejos, etc., que são costumeiramente atribuídas a alterações na imagem do corpo, podem ser causadas pela secreção incrementada de esteróide sexual, especialmente testosterona, encontrados em níveis elevados no sangue de meninos (Gates, 1918).

No meio do período da puberdade, os testículos e ovários normalmente segregam androgênios e estrogênios em taxas variáveis. Com estas variações muitos estudiosos acreditam que o desequilíbrio na secreção hormonal esteja associado a papéis sexuais divergentes na adolescente, como presença de identidade homossexual transitória e com a ocorrência deste fato, podem causar sérios problemas psicológicos (Dorfman, 1937).

Estima-se em 3 anos o período de maturação sexual no sexo masculino e de 3 a 4 anos no sexo feminino. A maturação sexual de meninas já foi estudada em diversas populações brasileiras, sendo a idade da menarca um dos parâmetros mais freqüentemente reportados, e essa idade é influenciada pelo: 1) nível de treinamento físico (atletas tem idade de menarca mais tardia), 2) tamanho da família (quanto maior mais tarde ocorre este fenômeno), 3) devido às condições socioeconômicas (quanto mais alto, mais precocemente ocorre a 
menarca), 4) menor percentual de gordura (menarca mais tardia). Há uma tendência da redução da idade da menarca tanto em países desenvolvidos como naqueles em desenvolvimento, chamando-se esse fato de "tendência secular", provavelmente devido às melhorias nas condições sanitárias, alimentares e habitacionais (Duarte, 1993).

Podem ocorrer problemas na puberdade como anormalidades de crescimento que é influenciado por diversos fatores, dentre eles a hereditariedade, fatores nutricionais e ambientais. Assim o crescimento do adolescente deve ser avaliado em intervalos maiores do que seis meses uma vez que o crescimento não é linear e constante durante os doze meses de um ano. Pode-se considerar desordens da puberdade, o atraso de desenvolvimento quando ainda não existe o broto mamário ou início do aumento dos testículos, até os 13 anos nas meninas e até os 14 anos nos meninos. Ainda, é considerada puberdade precoce quando os primeiros sinais de maturação sexual ocorrem antes dos 9 anos nos meninos e antes dos 8 anos nas meninas (Barbosa, 2004).

Os adolescentes desnutridos sofrem alterações de crescimento e retardo na maturação sexual (Bianculli, 1995) e as possíveis diferenças etárias neste processo podem se dar em função das características genéticas próprias de cada indivíduo e dos aspectos socioeconômicos e nutricionais (Saito, 1993).

Entre os 10 e 14 anos existem as maiores variações entre indivíduos em relação ao início, duração e magnitude da puberdade, sendo que nesta fase o maior condicionamento do crescimento e desenvolvimento é dado pela maturação sexual, que se traduz pelo desenvolvimento das características sexuais secundárias (Tanner, 1963; Malina, 1978; Saito, 1993; Duarte, 1993).

O aumento dos valores de IMC ao longo da adolescência pode ser interpretado como um marcador do amadurecimento orgânico, expresso pelo aumento na estatura e nas alterações da composição corporal. A diferença no ritmo de amadurecimento sexual entre os 
sexos é evidentemente maior no período até 15 anos, período esse de maior contraste, decrescendo depois, à medida que os estagiamentos de meninas e meninos se aproximam (Heald, 1975; Marino \& King, 1980)

Considerando o estudo de Guedes \& Guedes (1997) (apud,Waltrick \& Duarte,2000) constatou-se que meninas maturadas apresentam valores médios de massa corporal superiores para médias encontradas dentro da mesma idade, o que vem aludir que no início da adolescência ocorrem as maiores mudanças no organismo feminino, inclusive no acúmulo de gordura corporal, fato que incide pelas mudanças hormonais.

Em um estudo transversal que avaliou a composição corporal de 1348 jovens de acordo com seu estágio de maturação sexual, obteve-se o seguinte resultado: a menina ganha mais massa gorda e menos massa magra à medida que o IMC aumenta e o menino ganha massa magra e perde massa gorda. Proporcionalmente a menina ganha mais gordura e o menino mais tecido muscular (Castilho, 2004).

Deste modo, o início da adolescência é apontado como um dos momentos críticos para que se estabeleça a obesidade, tendo em vista não só o aumento de gordura, mas do próprio número de células (hiperplasia) que ocorre nesta fase, além de vir acompanhada de mudanças morfológicas e fisiológicas complexas na qual a nutrição tem papel extremamente importante (Muller, 2002).

\section{OBJETIVO}

Estimar a prevalência de excesso de peso em adolescentes de ambos os sexos na faixa etária de 10 a 14 anos considerando a maturação sexual em duas escolas públicas e duas escolas privadas da área urbana da cidade de Guarapuava - PR. 


\section{METODOLOGIA}

\subsection{Tipo de estudo}

Trata-se de um estudo transversal, não experimental de cunho quantitativo observacional e de variáveis quantitativas contínuas, onde foram avaliados adolescentes de 10 a 14 anos de ambos os sexos, alunos do ensino regular, devidamente matriculados em escolas públicas e privadas da cidade de Guarapuava-PR.

Sendo um estudo seccional, é possível produzir instantâneos da saúde de uma população, com base na avaliação individual do estado nutricional de cada um dos membros da amostra proporcionando desta forma indicadores globais para o grupo investigado (Almeida \& Rouquayrol, 2002).

\subsection{Local da pesquisa}

Duas escolas da rede pública e duas escolas da rede privada da zona urbana, da cidade de Guarapuava - PR foram sorteadas aleatoriamente. 
Descreve-se alguns aspectos da cidade de Guarapuava, onde estão localizadas as escolas da rede pública e privada de ensino onde estão os sujeitos que fizeram parte deste estudo.

O nome Guarapuava é derivado da língua indígena, que significa “Guará” lobo, "puava” bravo.

A cidade está situada na região centro sul paranaense, a $270 \mathrm{~km}$ da capital Curitiba e a $371 \mathrm{~km}$ de Paranaguá onde está um dos principais portos de escoamento de produtos de exportação do país.

Situa-se a $25^{\circ} 23^{\prime} 36^{\prime}$, latitude e a $51^{\circ} 27^{\prime} 19^{\prime \prime}$, longitude, tem uma superfície de $3.053,83 \mathrm{~km}^{2}$ e uma densidade demográfica de 50,31(hab/ $\left.\mathrm{km}^{2}\right)$, está a 1120 metros acima do nível do mar.

A população no ano de 2000 , era de 154.958 habitantes no total geral, sendo de 141.587 total urbana e 13.371 total rural, com 69.054 homens na área urbana e 7.079 na área rural, 72.533 mulheres na área urbana e 6292 na área rural, com uma população de adolescentes entre 10 à 19 anos de 30.908 (Dados do IBGE - 2000).

O relevo é suave ondulado a ondulado nas regiões de campo e ondulado a forte ondulado nas regiões de floresta. É cortado na divisa leste pela Serra da Esperança.

O solo predominante é Latossolo Bruno Álico e Litossolo, solos itálicos. Solos com elevada acidez, fertilidade natural de média a baixa, mas quando corrigida é altamente produtivo. No subsolo pode-se destacar a extração de pedra brita, e em alguns locais, argila. O Clima é subtropical úmido mesotérmico, de verões frescos e com ocorrência de geadas severas e freqüentes no inverno, não apresentando estação seca. A média da temperatura nos meses mais quentes é inferior a $22^{\circ} \mathrm{C}$ e dos meses frios é inferior a $18^{\circ} \mathrm{C}$, tendo uma temperatura média mínima de $12,6^{\circ} \mathrm{C}$ e $23,6^{\circ} \mathrm{C}$ média máxima. 
Guarapuava é um pólo regional, têm uma agricultura altamente tecnificada e uma pecuária com altíssima qualidade genética. Encontra-se em um grande entroncamento rodo ferroviário próximo dos principais centros econômicos do Mercosul.

A cidade é extremamente bem servida nas áreas de comunicações, saúde e educação. Existem atualmente três universidades e uma grande estrutura para a formação de mão-deobra técnica.

Há uma grande diversidade étnica e cultural.

O município apresenta bons indicadores sociais de educação e saúde, atualmente apresenta um índice de mortalidade infantil de 19 por mil nascidos vivos.

Dados da Secretaria Municipal de Educação revelam que, a rede pública de ensino possuiu no ano de 2004, 41 escolas urbanas, 14 escolas rurais, 16 projetos "Todo Tempo na Escola". Total de alunos da rede municipal neste mesmo ano foi de 22.064 , sendo 405 da zona rural, 15.554 da zona urbana, 2.044 alunos da pré-escola, 1.207 alunos dos Centros Municipais de Educação. Nos CMEIS (Centro de Educação Infantil), há 183 alunos de classe especial, 1.689 alunos no programa "Todo Tempo na Escola", 918 alunos no programa Jovens e Adultos entre outros programas de ensino especiais.

No município existem vários programas de políticas de saúde para a infância e adolescência.

\subsection{População}

A população do estudo era composta de 13.072 adolescentes de ambos os sexos matriculados nas escolas da rede pública e privada da área urbana, da cidade de GuarapuavaPR, sendo 12.186 da rede pública e 886 da rede privada (Anexo 1 e 2). 


\subsection{Procedimento amostral}

\subsubsection{Amostra}

A seleção da amostra obedeceu a critérios estatísticos, sob a orientação de um especialista da área. Considerando a prevalência de adolescentes obesos em torno de 0,20, buscou-se um erro de amostragem não superior a 5\% e nível de confiança de $95 \%$. Obteve-se então, para as escolas públicas um tamanho amostral de 273 alunos, estimando-se uma perda de $10 \%$ e cálculo para população finita, a amostra representativa final foi de 268 adolescentes. Para a rede privada, o tamanho amostral de 273 alunos com os mesmos cálculos da escola pública, amostra representativa de 208 adolescentes.

Sendo assim, a amostra total ficou definida em 476 adolescentes alunos de duas escolas públicas e duas escolas privadas.

Porém o retorno do termo de consentimento livre e esclarecido aos pais ou responsáveis, foi insuficiente para realizarmos a pesquisa . Foi necessário novo cálculo para definição da amostra, obtendo-se então para a escola pública 201 alunos com erro amostral de 5\% e nível de confiança de $95 \%$ e para as escolas privadas 185 alunos com o mesmo critério, ficando desta forma o tamanho amostral total de 386 alunos.

\subsubsection{Sorteio da amostra}

Primeiramente realizamos um levantamento junto a Secretaria Municipal de Educação da cidade, para obtermos dados numéricos das escolas da rede pública urbana. Para a rede privada foi realizado um levantamento no cadastro desta secretaria, porém os dados numéricos foram obtidos nas secretarias das respectivas escolas. Após buscamos autorização da Secretaria de Educação e dos respectivos diretores das escolas que ficaram conhecendo o detalhamento da pesquisa (Anexo 3). 
Tendo em vista a impossibilidade de avaliar todos os adolescentes das escolas realizou-se sorteio aleatório, entre as escolas que compõem a pública e a rede privada e também, sorteio aleatório das séries participantes do estudo.

Depois de definida a amostragem final da população, realizou-se um sorteio aleatório para as escolas públicas que ficaram assim determinadas: 1) Colégio Estadual Ana Vanda Bassara localizado no Bairro Santana, com um total de 476 alunos de $5^{\mathrm{a}}$ a $8^{\mathrm{a}}$ séries. 2) Colégio Estadual Manoel Ribas, localizado no centro da cidade, com um total 546 alunos de $5^{\mathrm{a}}$ à $8^{\mathrm{a}}$ séries. O mesmo se fez para as escolas privadas que ficaram assim definidas: 1) Colégio Adventista localizado no bairro Batel, com um total de 105 alunos de $5^{\mathrm{a}}$ a $8^{\mathrm{a}}$ séries. 2) Colégio Aliança, localizado no Bairro Santana, com um total de 315 alunos. Neste último colégio foram sorteadas também duas séries de $1^{\mathrm{o}}$ ano de segundo grau por possuírem alunos enquadrados dentro da faixa etária pesquisada (Anexo 4 e 5).

Posterior ao sorteio para definição das escolas, o mesmo se fez para definir as séries participantes.

\subsection{Coleta de dados}

Antes da coleta de dados foi enviado aos pais o Termo de Consentimento Livre e Esclarecido (Anexo 6) aprovado pelo Comitê de Ética em Pesquisa da Escola de Enfermagem de Ribeirão Preto -USP (Protocolo- n 0468/2004). Foram portadores desse documento os alunos das séries sorteadas.

Após esse procedimento, foram coletados dados de peso e altura dos sujeitos, nas próprias instituições, dispondo-se de instrumentos simples, como uso de balança de plataforma e de travessão com pesos móveis, aproximação de 100 g da Marca Filizola, capacidade para $150 \mathrm{~kg}$ para medida de peso sendo que os adolescentes estavam com roupas leves. A balança foi devidamente aferida por um técnico antes da coleta de dados, e após cada 
transporte para as devidas instituições, sendo a mesma calibrada com pesos conhecidos. Realizou-se calibragem manual após cada pesagem.

Para a medida de estatura, utilizou-se fita métrica inelástica, com escala de medidas até $150 \mathrm{~cm}$ e capacidade de uma exatidão de até $0,1 \mathrm{~cm}$, fixada em posição vertical na parede. Os adolescentes estavam descalços, em pé sobre uma superfície plana, com os pés paralelos, calcanhares, músculos glúteos, ombros e parte posterior da cabeça tocando a fita. Os olhos foram alinhados com o ápice das orelhas, formando um ângulo reto com a parede e a leitura da estatura foi feita com o auxílio de uma prancheta, pressionando o cabelo até tocar a cabeça.

A coleta dos dados foi efetuada por acadêmicos do Curso de Nutrição da UNICENTRO- Guarapuava - PR devidamente instruídos sobre conceitos e procedimentos para medir a composição corporal, medindo apenas pontos padronizados. Os mesmos foram selecionados a partir de $90 \%$ de concordância com o calibrador, que neste caso foi o pesquisador. Para isso, realizou-se um estudo piloto com 05 alunos de cada escola participante da pesquisa. Neste estudo, coletaram-se dados antropométricos de peso e altura e também perguntou-se questão referente a maturação sexual. Está última questão foi definida da seguinte forma: ocorrência de menarca para sexo feminino e presença de pêlos axilares para o sexo masculino e a idade quando estes fatos ocorreram. Os dados demográficos relativos a idade dos participantes, foi obtida através dos alunos com a informação da data de nascimento.

O instrumento para a coleta de dados encontra-se em anexo (Anexo 7) e a mesma foi realizada nos meses de setembro e outubro de 2004.

\subsection{Análise dos dados}

As variáveis utilizadas foram o sexo, idade em anos de vida, origem das escolas alunos de escola (pública ou privada), IMC calculado a partir do peso e altura e presença ou ausência de maturação sexual. 
Para classificação de sobrepeso e obesidade foram considerados os valores de IMC apresentados no quadro abaixo, segundo Must (1991).

QUADRO 1. Valores de IMC segundo os percentis 85 e 95 de acordo com sexo e idade.

\begin{tabular}{|c|c|c|c|c|}
\hline $\begin{array}{l}\text { Idade } \\
\text { Anos } \\
\end{array}$ & \multicolumn{2}{|c|}{$\begin{array}{l}\text { Percentil } 85 \\
\text { Sobrepeso } \\
\end{array}$} & \multicolumn{2}{|c|}{$\begin{array}{l}\text { Percentil } 95 \\
\text { Obesidade }\end{array}$} \\
\hline & Masculino & Feminino & Masculino & Feminino \\
\hline 10 & 19,60 & 20,19 & 22,60 & 23,20 \\
\hline 11 & 20,35 & 21,18 & 23,73 & 24,59 \\
\hline 12 & 21,12 & 22,17 & 24,89 & 25,95 \\
\hline 13 & 21,93 & 23,08 & 25,93 & 27,07 \\
\hline 14 & 22,77 & 23,88 & 26,93 & 27,97 \\
\hline
\end{tabular}

Fonte: Must et al. Am J Clin Nutrition 53, 1991: 839-46, 1991 e vol. 54, 1991: 773

O sobrepeso foi definido quando o IMC era igual ou superior ao percentil 85 e menor que o 95 para idade e sexo e obesidade quando o percentil era igual ou superior ao 95 .

Os dados foram inicialmente digitados em duplicata em planilha Excel ${ }^{\circledR}$ e o banco de dados foi convertido para o programa SPSS 10.0.

Foram obtidas freqüências simples de todas as variáveis para verificação de amplitude e consistência. Em seguida, as variáveis foram rotuladas e editadas para análise.

Foram construídas as variáveis idade - a partir das datas de nascimento e de coleta dos dados - e IMC - dividindo-se o peso (em $\mathrm{Kg}$ ) pela altura (em metros ao quadrado).

Para as variáveis quantitativas, obtiveram-se medidas de tendência central e os histogramas de distribuição. 

da cidade de Guarapuava -PR

A associação entre as variáveis foi obtida pelo teste do qui-quadrado e foram calculadas no programa EPIINFO 6.04 as razões de prevalência e os intervalos de confiança de $95 \%$, para escolas públicas e privadas. 


\section{RESULTADOS}

\subsection{Características demográficas}

Foram incluídos no presente estudo 386 alunos entre 10 e 14 anos, oriundos de quatro escolas de Guarapuava - PR, sendo duas públicas e duas privadas.

A Tabela 1 apresenta a distribuição da amostra segundo suas características demográficas. Pode-se observar que a maior representatividade ficou para adolescentes de 13 anos, com $26 \%$ e a mínima para adolescentes de 10 anos com 7,5\% . A média para as idades foi de 12,9 anos $( \pm 1,22)$ e mediana de 13,02 anos.

Tabela 1. Distribuição da amostra conforme a idade e o sexo. Guarapuava - PR,

2004.

\begin{tabular}{cccc}
\hline & Variável & $\mathrm{N}$ & $\%$ \\
\hline Idade (anos) & & \\
10 & 29 & 7,5 \\
11 & 70 & 18,1 \\
12 & 91 & 23,6 \\
& 13 & 102 & 26,4 \\
& 14 & 94 & 24,4 \\
Sexo & & & \\
& Masculino & 182 & 47,2 \\
& Feminino & 204 & 52,8 \\
& & & \\
\hline Total & & 386 & 100,0 \\
\hline
\end{tabular}

A Tabela 2 apresenta a distribuição da amostra conforme a escola e a série que os alunos estavam freqüentando. Observou-se equilíbrio entre públicas e privadas, pouco mais da 
metade pertencia a escolas públicas, sendo que a escola Manoel Ribas ficou com a maior representação - quase 30\% - e a escola Adventista ficou com a menor - 22\%.

Cerca de um terço dos alunos estavam na sexta série do ensino fundamental e apenas 4,9\% estavam na primeira série do ensino médio.

Tabela 2. Distribuição da amostra conforme a escola e a série.

Guarapuava - PR,

2004.

\begin{tabular}{|c|c|c|}
\hline Variável & $\mathrm{N}$ & $\%$ \\
\hline \multicolumn{3}{|l|}{ Escola } \\
\hline Adventista & 85 & 22,0 \\
\hline Aliança & 100 & 25,9 \\
\hline Ana Vanda Bassara & 89 & 23,1 \\
\hline Manoel Ribas & 112 & 29,0 \\
\hline
\end{tabular}

Tipo de escola

Privada

Pública

201

52,1

Série

$\begin{array}{lcc}\text { Quinta } & 69 & 17,9 \\ \text { Sexta } & 134 & 34,7 \\ \text { Sétima } & 94 & 24,4 \\ \text { Oitava } & 70 & 18,1 \\ \text { Primeira (ensino médio) } & 19 & 4,9\end{array}$

Total

386 
As figuras a seguir apresentam as diferenças nas características dos alunos (idade e sexo) de acordo com a rede de ensino - pública ou privada.

Nas escolas privadas de acordo com o sexo, 92 eram do sexo masculino e 93 eram do sexo feminino, enquanto que nas escolas públicas 90 eram do sexo masculino e 111 eram do sexo feminino, conforme figura 1.

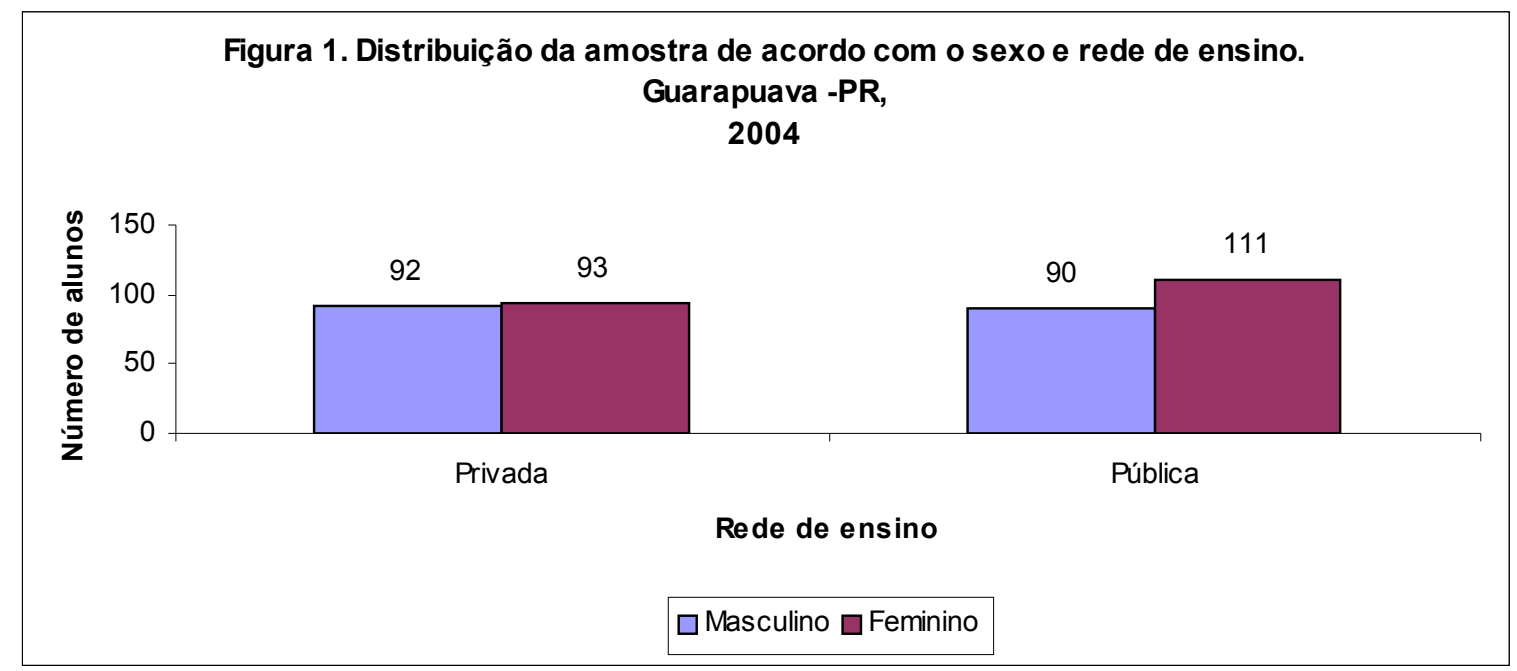

Nas escolas privadas, 12 alunos tinham 10 anos de idade, 32 alunos tinham 11 anos, 41 tinham 12 anos, 56 tinham 13 anos e 44 tinham 14 anos. Nas escolas públicas 17 alunos tinham 10 anos, 38 tinham 11 anos, 50 tinham 12 anos, 46 tinham 13 anos e 50 tinham 14 anos, conforme figura 2. 
Figura 2. Distribuição da amostra de acordo com a idade e a rede de ensino.

Guarapuava- PR, 2004.

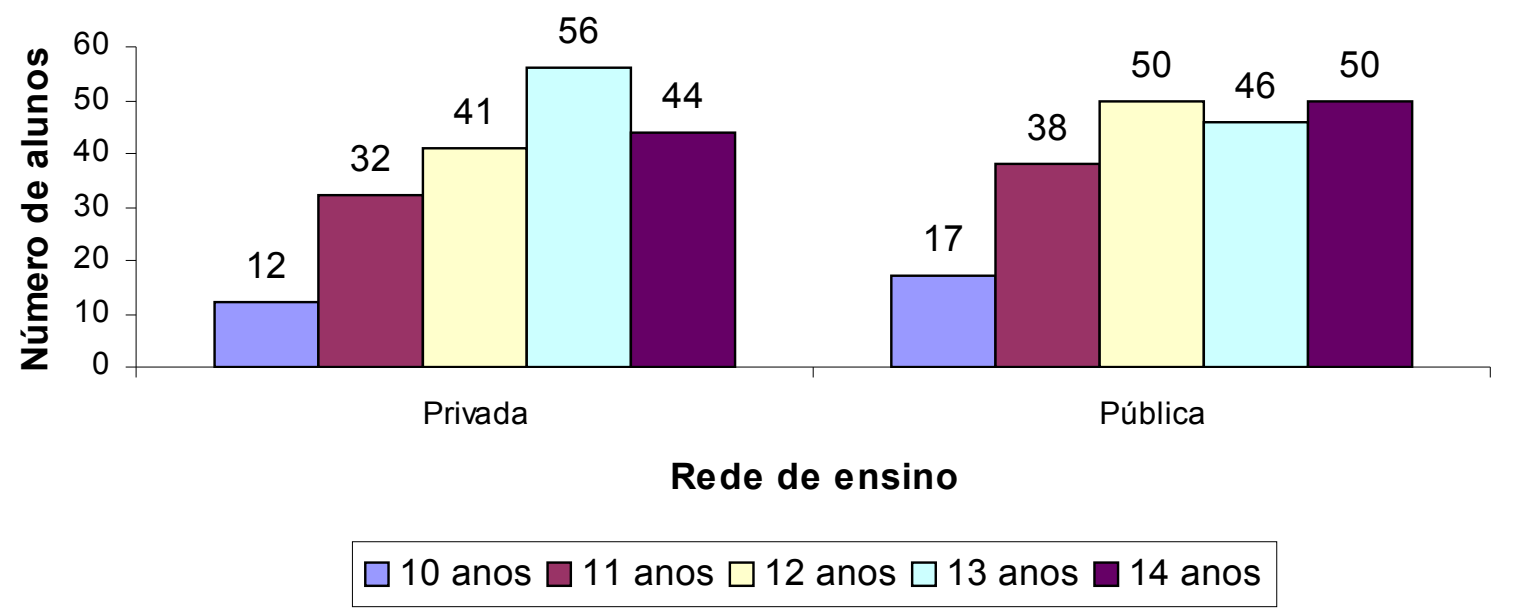

\subsection{Características antropométricas}

As Figuras 3 a 5 apresentam os histogramas das distribuições de peso, altura e Índice de Massa Corporal dos alunos estudados.

A distribuição de peso registrou média de 47,2 kg ( $\pm 10,8 \mathrm{~kg})$ e mediana de 46,5 kg, o que permite concluir pela normalidade da distribuição. O peso mínimo foi de $24,2 \mathrm{~kg}$ e o máximo de $85,7 \mathrm{Kg}$. 
Figura 3. Histograma dos pesos dos alunos incluídos na amostra. Guarapuava, PR, 2004.

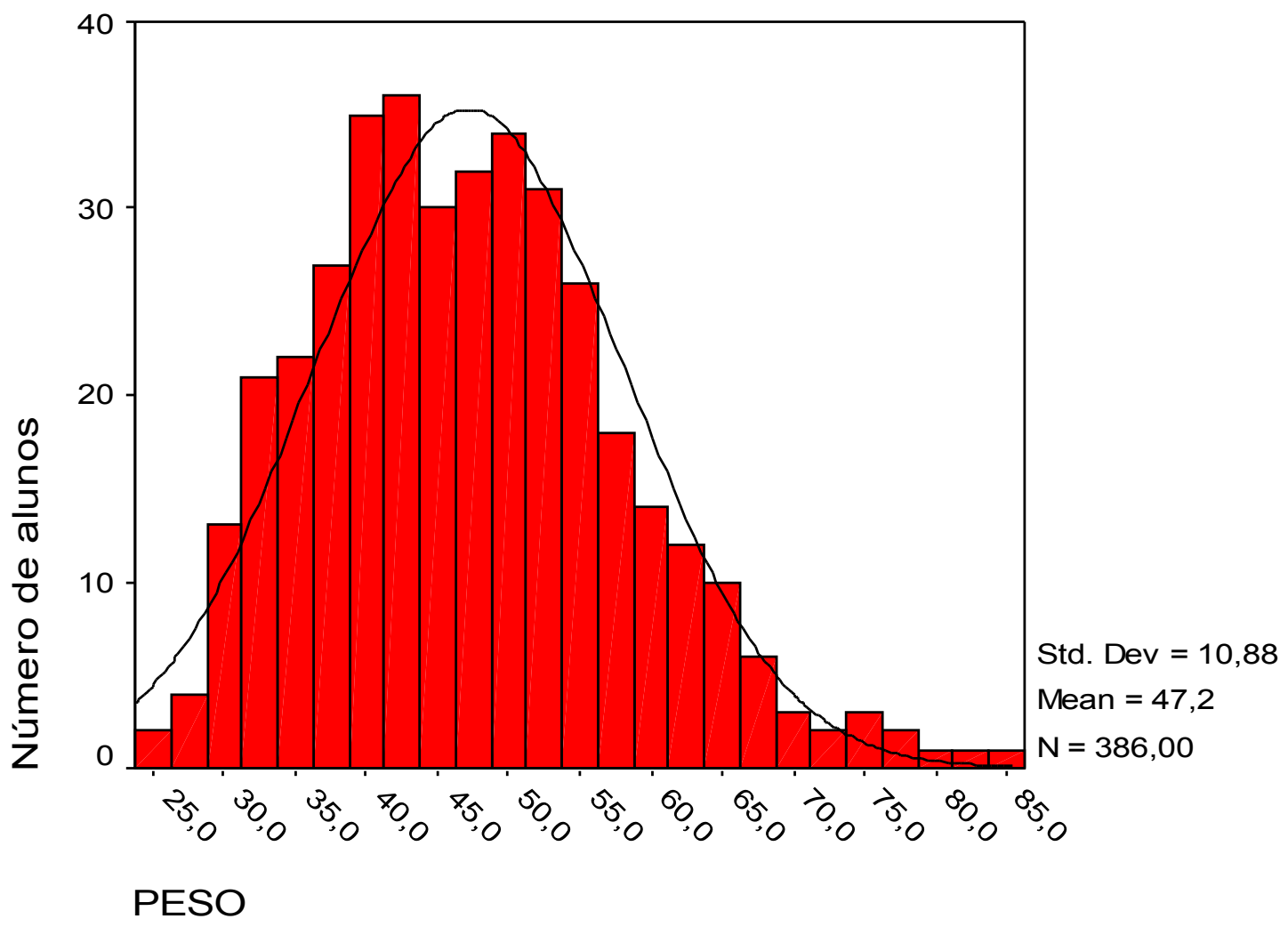

A altura média foi de $1,55 \mathrm{~m}$ e mediana dos alunos foi de $1,56 \mathrm{~m}( \pm 0,09 \mathrm{~m})$. $\mathrm{O}$ aluno mais baixo mediu 1,30 m e o mais alto $1,84 \mathrm{~m}$. Da mesma forma que o peso, a distribuição de altura foi bastante simétrica em torno da média.

Figura 4. Histograma das alturas dos alunos incluídos na amostra.

Guarapuava, PR, 2004. 


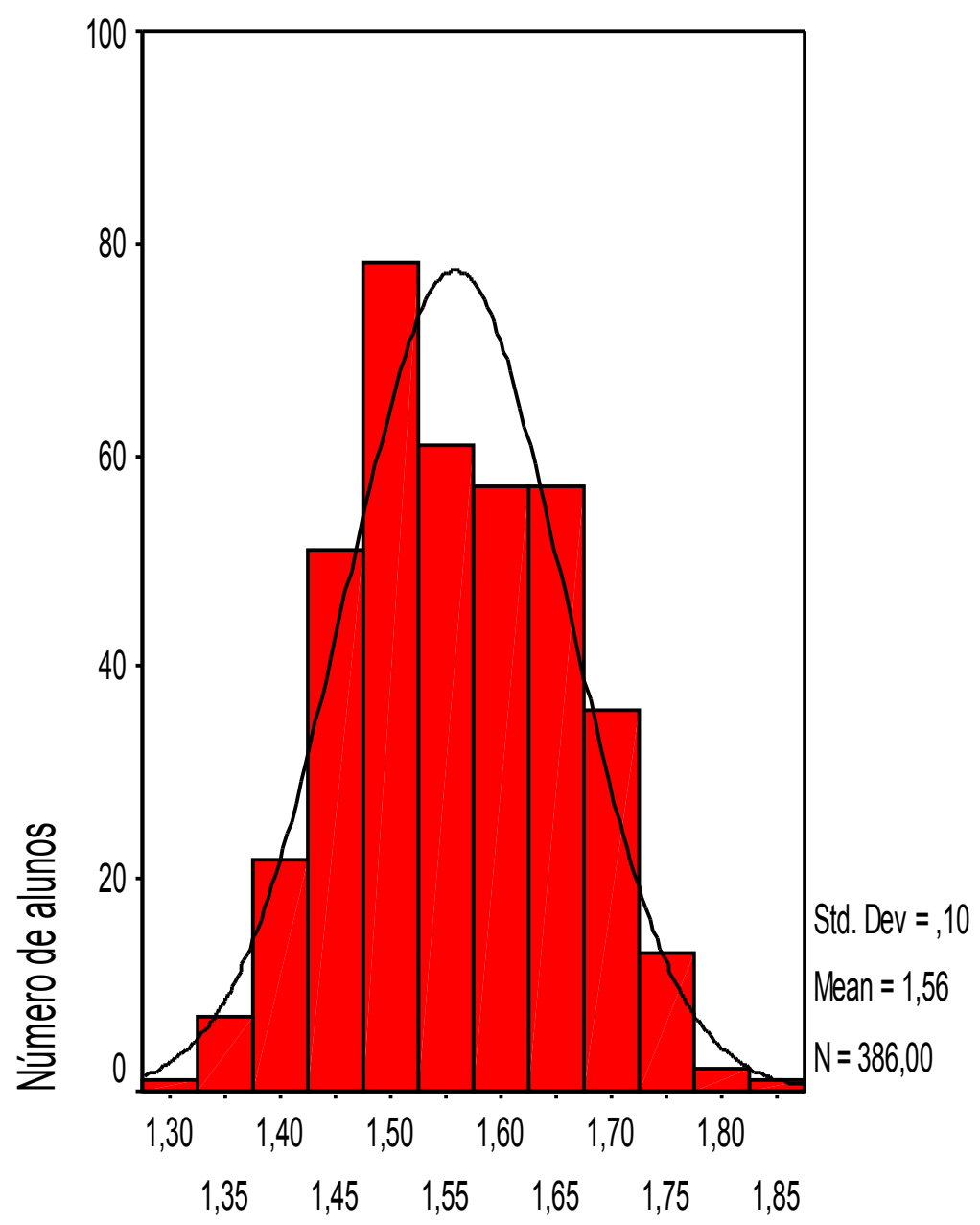

ALTURA 
A relação entre o peso e a altura foi avaliada pelo IMC, cuja média para esta amostra ficou em $19,24 \mathrm{Kg} / \mathrm{m}^{2}\left( \pm 3,14 \mathrm{Kg} / \mathrm{m}^{2}\right)$ e a mediana ficou em $18,8 \mathrm{Kg} / \mathrm{m}^{2}$. A medida mais baixa para este índice foi de $13,3 \mathrm{Kg} / \mathrm{m}^{2}$ e a mais alta foi de $34,8 \mathrm{Kg} / \mathrm{m}^{2}$.

Figura 5. Histograma dos Índices de Massa Corporal dos alunos incluídos na amostra. Guarapuava, PR, 2004.

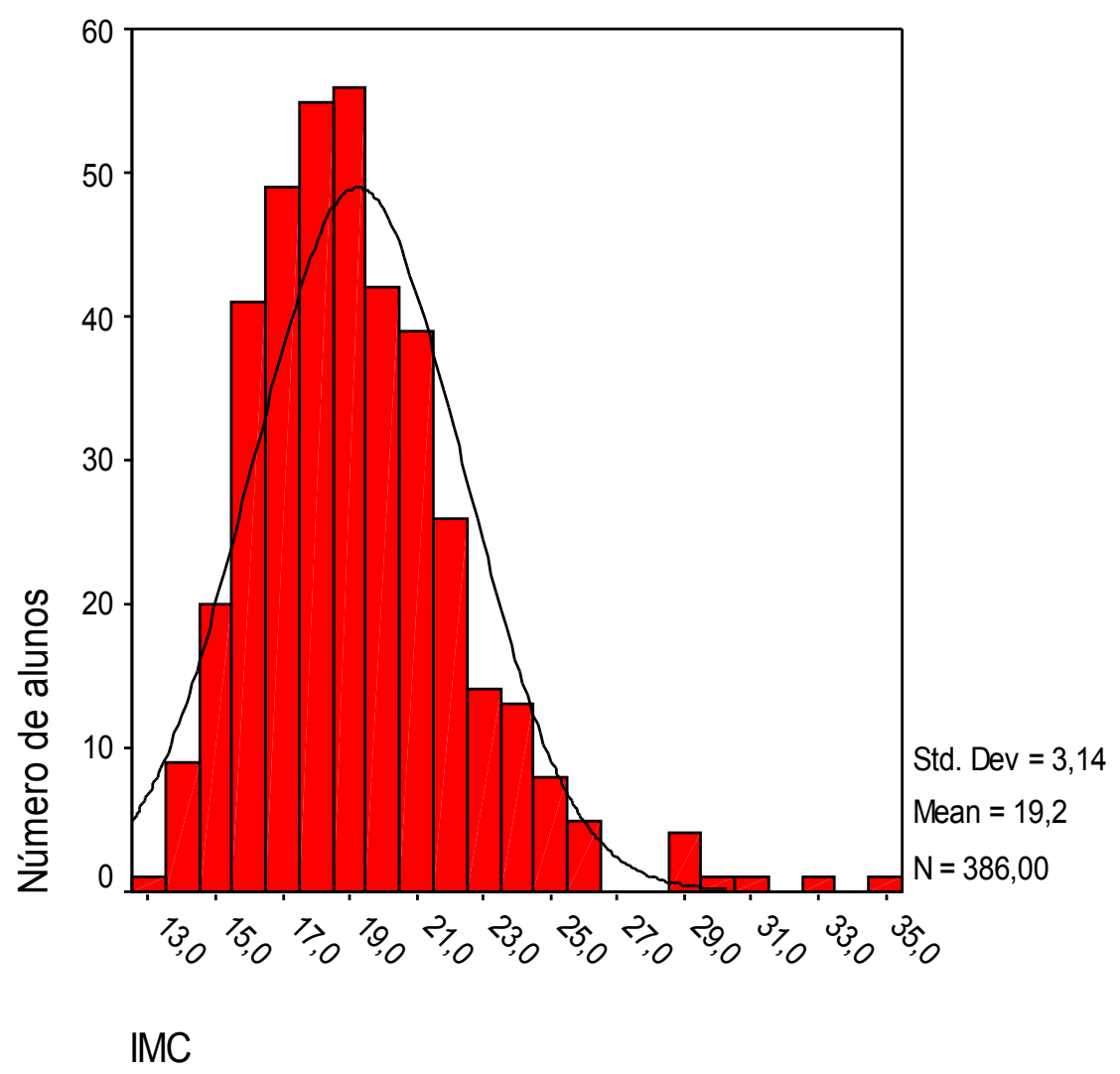

Mesmo não sendo o objetivo do trabalho definir IMC, para baixo peso, pode-se observar que pela curva não totalmente simétrica ocorreu casos de baixo peso.

A situação antropométrica dos adolescentes estudados e a ocorrência de sua maturação sexual são apresentadas na Tabela 3. 
Tabela 3. Distribuição da amostra conforme a maturação sexual e a situação antropométrica.

Guarapuava - PR,

2004.

\begin{tabular}{ccc}
\hline \multicolumn{1}{c}{ Variável } & $\mathrm{N}$ & $\%$ \\
\hline Maturação sexual & & \\
Sim & 190 & 49,2 \\
Não & 196 & 50,8 \\
Situação antropométrica & & \\
Sobrepeso & 50 & 13,0 \\
Obesidade & 13 & 3,4 \\
\hline Total & 73 & 16,4 \\
\hline
\end{tabular}

A maioria dos adolescentes, ou seja , 323 não apresentaram percentual de excesso de peso ficando enquadrados como eutróficos na maioria dos casos e outros em menor número poderiam ser enquadrados como baixo peso.

A prevalência de sobrepeso foi de $13,0 \%$ e a de obesidade foi de 3,4\%. Praticamente a metade das crianças apresentava sinais de maturação sexual $(49,2 \%)$ - menarca para as meninas e presença de pelos axilares para os meninos. A maturação sexual ocorreu em média aos 11,9 anos com mediana de 12 anos e desvio padrão de 1,00. A idade mínima ocorreu aos 9 anos e a máxima aos 14 anos. De acordo com o sexo 42,2\% dos meninos eram maturados e 57,7\% não maturados, com média de 12,2 anos $( \pm 0,9)$ e mediana de 12 anos a idade mínima de ocorrência de maturação para este sexo foi de 10 anos e a máxima de 14 anos. Nas meninas 55,5\% eram maturadas e 44,6 não maturadas, com media de 11,83 anos $( \pm 1,03)$ e mediana de 12 anos, idade mínima de ocorrência de 9 anos e máxima de 14 anos. Conforme a idade a maior prevalência de sobrepeso ocorreu aos 12 anos com $15,6 \%$. 
Tabela 4. Prevalência de sobrepeso conforme a idade e o sexo.

Guarapuava - PR, 2004.

\begin{tabular}{ccc}
\hline Variável & $\begin{array}{c}\text { \% de } \\
\text { sobrepeso }\end{array}$ \\
\hline Idade (anos) & \\
10 & 13,5 \\
11 & 12,2 \\
12 & 15,6 \\
& 13 & 12,2 \\
& 14 & 11,0 \\
Sexo & & \\
& Masculino & 14,8 \\
& Feminino & 11,3 \\
\hline Total & & 13,0 \\
\hline
\end{tabular}

Em relação ao sexo, a maior prevalência de sobrepeso foi no sexo masculino com $14,8 \%$ enquanto as meninas apresentaram um percentual de $11,3 \%$ (Tabela 4 ).

As diferenças observadas na amostra foram relativas às prevalências de obesidade conforme o sexo, onde os meninos apresentaram mais que o dobro de obesidade do que as meninas.(Tabela 5).

Tabela 5. Prevalência de obesidade conforme a idade e o sexo. Guarapuava - PR, 2004.

\begin{tabular}{|c|c|}
\hline \multicolumn{2}{|l|}{ Idade (anos) } \\
\hline 10 & 2,7 \\
\hline 11 & 6,1 \\
\hline 12 & 3,1 \\
\hline 13 & 4,1 \\
\hline 14 & 0,0 \\
\hline \multicolumn{2}{|l|}{ Sexo } \\
\hline Masculino & 4,9 \\
\hline Feminino & 2,0 \\
\hline Total & 3,4 \\
\hline
\end{tabular}


Alunos que estudavam nas escolas privadas, Adventista e Aliança apresentaram maior percentual de sobrepeso em relação às escolas públicas, porém sem diferenças estatisticamente significativa. De acordo com o tipo de escola as privadas obtiveram um percentual de $16,2 \%$ e as escolas públicas $10 \%$, sem diferença estatisticamente significativa (Tabela 6).

Tabela 6. Prevalência de sobrepeso conforme a escola.

Guarapuava - PR,

2004.

\begin{tabular}{|c|c|c|c|c|}
\hline \multicolumn{2}{|r|}{ Variável } & $\begin{array}{c}\% \text { de } \\
\text { sobrepeso }\end{array}$ & $\begin{array}{l}\text { Razão de } \\
\text { prevalências } \\
(\text { IC } 95 \%)\end{array}$ & p-valor \\
\hline \multicolumn{5}{|c|}{ Escola } \\
\hline & Adventista & 20,0 & $2,01(1,00-4,06)$ & 0,07 \\
\hline & Aliança & 13,0 & $1,34(0,63-2,86)$ & 0,58 \\
\hline & Ana V.Bassara & 10,1 & $1,02(0,44-2,34)$ & 0,84 \\
\hline & Manoel Ribas & 9,8 & 1,00 & \\
\hline \multicolumn{5}{|c|}{ Tipo de escola } \\
\hline & Privada & 16,2 & $1,64(0,97-2,79)$ & 0,09 \\
\hline & Pública & 10,0 & 1,00 & \\
\hline Total & & 13,0 & -- & -- \\
\hline
\end{tabular}


Os alunos que estudavam na oitava série foram os que obtiveram os maiores percentuais de sobrepeso, em seguida os alunos de quinta série, e os que estudavam na sexta série foram os que obtiveram menores percentuais (Tabela 7).

Tabela 7. Prevalência de sobrepeso conforme a série.

Guarapuava - PR, 2004

\begin{tabular}{llc}
\hline & Variável & $\begin{array}{c}\text { \% de } \\
\text { sobrepeso }\end{array}$ \\
\hline Série & & \\
& Quinta & 15,9 \\
& Sexta & 10,4 \\
& Sétima & 11,7 \\
& Oitava & 17,1 \\
& Primeira (ensino & 10,5 \\
& médio) & \\
\hline Total & & 13,0 \\
\hline
\end{tabular}


Em relação à prevalência de obesidade, o maior percentual foi observado na escola Aliança, porém sem diferença estatisticamente significativa entre escolas públicas e privadas (Tabela 8).

Tabela 8. Prevalência de obesidade conforme a escola.

Guarapuava - PR,

2004.

\begin{tabular}{|c|c|c|c|c|}
\hline \multicolumn{2}{|r|}{ Variável } & $\begin{array}{c}\% \text { de } \\
\text { obesidade }\end{array}$ & $\begin{array}{l}\text { Razão de } \\
\text { prevalências } \\
\text { (IC 95\%) }\end{array}$ & p-valor \\
\hline \multicolumn{5}{|c|}{ Escola } \\
\hline & Adventista & 2,4 & $0,74(0,14-3,94)$ & 0,94 \\
\hline & Aliança & 5,0 & $1,45(0,40-5,24)$ & 0,82 \\
\hline & Ana V.Bassara & 2,2 & $0,63(0,12-3,36)$ & 0,89 \\
\hline & Manoel Ribas & 3,6 & 1,00 & \\
\hline \multicolumn{5}{|c|}{ Tipo de escola } \\
\hline & Privada & 3,8 & $1,36(0,47-3,97)$ & 0,78 \\
\hline & Pública & 3,0 & 1,00 & \\
\hline Total & & 3,4 & -- & -- \\
\hline
\end{tabular}


O percentual de obesidade não apresentou diferenças importantes de acordo com a série freqüentada.O maior percentual ficou com a sexta série e sem nenhum caso na primeira série do ensino médio (Tabela 9).

Tabela 9. Prevalência de obesidade conforme a série. Guarapuava - PR, 2004.

\begin{tabular}{llc}
\hline & Variável & $\begin{array}{c}\text { \% de } \\
\text { obesidade }\end{array}$ \\
\hline Série & & \\
& Quinta & 2,9 \\
& Sexta & 5,2 \\
& Sétima & 2,1 \\
& Oitava & 2,9 \\
& Primeira & $($ ensino \\
& médio) & 0,0 \\
\hline Total & & 3,4 \\
\hline
\end{tabular}

Observou-se maior prevalência de sobrepeso nos maturados com percentual de 18,4\% os não-maturados obtiveram um percentual de 7,7\% (Tabela 10). Dos adolescentes maturados 70\% apresentaram sobrepeso o mesmo não acontecendo em relação à obesidade, onde os percentuais foram semelhantes, $46,15 \%$ para maturados e $53,85 \%$ para não maturados (Tabela 11).

Tabela 10. Prevalência de sobrepeso conforme a maturação sexual.

Guarapuava - PR,

2004.

\begin{tabular}{ccc}
\hline Variável & $\begin{array}{c}\text { \% de } \\
\text { sobrepeso }\end{array}$ \\
\hline Maturação sexual & \\
Sim & 18,4 \\
& Não & 7,7 \\
\hline Total & 13,0 \\
\hline
\end{tabular}


Tabela 11. Prevalência de obesidade conforme a maturação sexual.

Guarapuava - PR, 2004.

\begin{tabular}{ccc}
\hline Variável & $\begin{array}{c}\text { \% de } \\
\text { obesidade }\end{array}$ \\
\hline Maturação sexual & \\
Sim & 3,2 \\
& Não & 3,6 \\
\hline Total & 3,4 \\
\hline
\end{tabular}

O maior percentual de obesidade ocorreu na Escola Aliança, sendo está da rede privada e o menor percentual na Escola Ana Vanda Bassara que é da rede pública.

Nesta amostra, foram observadas diferenças percentuais na prevalência de obesidade conforme o sexo - meninos são mais obesos do que meninas - e na prevalência de sobrepeso conforme o tipo de escola - alunos de escolas privadas apresentaram mais sobrepeso do que os de escolas públicas.

Em relação à maturação sexual, somente o sobrepeso foi significativamente mais prevalente $(70 \%)$ entre quem já apresentava sinais de maturação sexual. Quanto à prevalência de obesidade $46,15 \%$ dos adolescentes maturados eram obesos. 


\section{DISCUSSÃO}

O objetivo deste estudo foi estimar a prevalência de excesso de peso em adolescentes de ambos os sexos na faixa etária de 10 a 14 anos em duas escolas públicas e duas escolas privadas da área urbana da cidade de Guarapuava - PR

No Brasil, a comparação de dois inquéritos nacionais realizados em 1974/75 e 1996/97 revelou que a prevalência de sobrepeso aumentou de 3,7\% para $12,6 \%$ em adolescentes entre 10 e 18 anos.

Outros estudos populacionais com adolescentes em algumas capitais do Brasil mostram uma tendência para o crescimento de obesidade, com diferentes percentuais que variam de 4,2\% no Recife-PE a 22,3\% em Florianópolis (Lamonier, 2000)

No presente estudo encontrou-se um total de $13,0 \%$ de sobrepeso e $3,4 \%$ de obesidade para adolescentes de ambos os sexos. Estudos de prevalência de excesso de peso são muito variados, indo de $4 \%$ até $20 \%$ nas diferentes regiões do país.

Um estudo transversal, que investigou a dieta habitual de crianças e adolescentes com sobrepeso e obesidade avaliados pelo cálculo do IMC, concluiu que estes possuem uma alimentação inadequada com elevada ingestão de proteínas e lipídios e deficiente em fibras. Os autores observaram que mães com maior nível de escolaridade incorporam conhecimentos adequados sobre nutrição e passam a alimentar os filhos de forma mais equilibrada, resultando em menor freqüência de obesidade. Esse processo resultou em decrescente prevalência de obesidade ( 9,9\% em 1989 para 4,5\% em 1993) sugerindo que o excesso de peso tem origem exógena corroborando dados da literatura que indicam ser causas de aumento de excesso de peso em adolescentes (Chaul et al., 2000).

Segundo Bray e Popkin (apud Lima et al., 2004), os fatores etiológicos que explicam o aumento do número de obesos no mundo estão ligadas as mudanças no estilo de vida com hábitos alimentares inadequados. Neste contexto a diminuição na prática de exercícios físicos 
e o aumento da ingestão de alimentos gordurosos são os dois principais fatores que colaboram para tal quadro.

Analisando os resultados encontrados neste estudo em relação ao sexo, o sobrepeso esteve presente em $14,8 \%$ dos meninos e $11,3 \%$ das meninas. Quanto à obesidade, dos $3,4 \%$ da amostra total, $4,9 \%$ era do sexo masculino e $2,0 \%$ era do sexo feminino.

Pudemos observar resultados similares ao estudo transversal com adolescentes em escola de classe média/alta em Recife-PE, onde a prevalência para sobrepeso foi de $20 \%$ e 4,2\% para obesidade, sendo também maior em adolescentes do sexo masculino (Balaban \& Silva, 2000).

Outro estudo realizado em Guarulhos-SP com 130 adolescentes do sexo feminino e 70 do sexo masculino entre 10 e 12 anos, mostrou alta prevalência de sobrepeso em meninos $(60 \%)$ comparada a das meninas $(25 \%)$ coincidindo com maior taxa para o sexo masculino assim como no presente estudo (Gasparini, 2003)

Seguindo a mesma tendência, um estudo transversal com todos os alunos de escola de classe média com adolescentes de 15 a 17 anos foi realizado por Fonseca et al., (1998) na cidade de Niterói - RJ obtendo como resultados 23,9\% de sobrepeso para meninos e 7,2\% para meninas. Nessas, o maior IMC associou-se à omissão de desjejum e nos meninos, com horas assistindo televisão ou jogando vídeo game.

Estudo transversal com adolescentes de 12 a 17 anos de escola de classe média/alta realizado na cidade de Montes Claros - MG, encontraram maiores índices de sobrepeso onde $30,9 \%$ eram meninos e $12,1 \%$ eram meninas (Nunes \& Pereira, 2000).

Priore na cidade de São Paulo-SP, avaliou adolescentes de 7 a 17 anos de escolas públicas encontrando através do cálculo de IMC maior prevalência de sobrepeso no sexo masculino do que no feminino (Lamonier, 2000) 
Outro estudo realizado por Santos, (2003) com adolescentes da rede pública e privada de ensino do município de Ribeirão Preto-SP, encontrou sobrepeso maior do que obesidade e também, maior prevalência dessas situações no sexo masculino comparado com o sexo feminino, sendo similar ao encontrado no nosso estudo.

O estudo desenvolvido em Manaus com adolescentes na faixa etária de 10 a 12 anos, encontrou $14 \%$ de obesidade para o sexo masculino e $6 \%$ para o sexo feminino, e na faixa etária de 13 a 15 anos os valores foram de $20 \%$ de obesidade no sexo masculino e 7,5\% no sexo feminino (Lamonier, 2000).

Na mesma tendência pesquisa realizada por Lamonier (1999) em prontuários médicos na cidade de Belo Horizonte - MG a prevalência total de sobrepeso foi de 21,3\% para o sexo masculino e $16,7 \%$ para o sexo feminino.

Resultados similares também foram encontrados em adolescentes do Ambulatório da Adolescência do Hospital de Clínicas da Universidade Federal de Minas Gerais, onde 21,3\% de sobrepeso foi no sexo masculino e $16,7 \%$ foi no sexo feminino (Chaul \& Cunha apud Lamonier et al., 1999).

$\mathrm{Na}$ avaliação de reservas adiposas de adolescentes pode estar embutido massa muscular determinando aumento de prevalência do excesso de peso em homens e baixa prevalência de excesso de peso em mulheres (Frisancho, 1990).

No entanto, há trabalhos que identificaram prevalência maior no sexo feminino realizados por Goldberg et al. (1996) e Garcia et al. (2000) (apud Lamonier, 2000).

O crescimento muscular máximo ocorre no pico do estirão no sexo masculino e no sexo feminino após o estirão, juntamente com a menarca. A massa muscular magra é quantitativamente maior no sexo masculino em comparação com o sexo feminino. A velocidade de ganho de gordura atinge valores mínimos na época de estirão, principalmente 
nos meninos quando pode ocorrer perda real de gordura. Quando o pico de velocidade de crescimento é alcançado, ocorre aumento rápido de acúmulo de gordura no sexo feminino, chegando a ser o dobro em relação ao sexo masculino no final da maturação sexual (Oliveira, et al., 1997).

Em pesquisa realizada por Abrantes et al. (apud Mello et al., 2004) nas regiões Sudeste e Nordeste em 2002, houve prevalência de obesidade de $10,3 \%$ e 9,3\% para o sexo feminino e masculino respectivamente.

Contudo, as diferenças observadas nas prevalências de excesso de peso utilizando o IMC como parâmetro, podem estar expressando dificuldade de classificação do próprio indicador para o IMC. Portanto, a utilização de metodologias que avaliem de forma mais minuciosa a composição corporal se torna fundamental para o diagnóstico de excesso de peso em adolescentes.

Considerando a realidade dos recursos disponíveis nos serviços de saúde do nosso país, percebe-se que é necessária a utilização de critério diagnóstico simples e de baixo custo, justificando assim, a escolha da metodologia utilizada neste trabalho com dados antropométricos (peso, altura e IMC) e o diagnóstico a partir dos limites propostos por Must et al., 1991.

Em estudos populacionais, a antropometria mesmo quanto restrita ao peso e estatura constitui importante método diagnóstico fornecendo estimativa de prevalência e gravidade das alterações nutricionais, pois estes dados são de fácil realização e objetividade das medidas e os pontos de cortes propostos por Must (1991) consiste em um dos índices mais utilizados para avaliação do sobrepeso em adolescentes na rotina em Saúde Pública (Sotello et al., 2004). 
No entanto falta de unanimidade nos critérios apontados na literatura para definição da obesidade infantil e na adolescência, indicando a necessidade de estabelecer pontos de corte específicos para cada população.

A OMS reconhece que, embora o IMC, seja o indicador de gordura corporal total ele deve associar-se à classificação de maturação sexual e das dobras subcutâneas triciptal e subescapular com ponto de corte no percentil 90. Entretanto é difícil a mensuração das pregas cutâneas nos serviços de saúde, de forma que a utilização da classificação tende a basear-se no uso exclusivo do IMC (Chiara et al., 2003).

Observam-se diversos estudos abordando resultados que indicam maior prevalência de sobrepeso e obesidade nas redes de ensino privado, e ao que tudo indica é devido as melhores condições econômicas destes adolescentes. Na cidade de Salvador em 2002, pesquisa realizada com crianças e adolescentes encontrou prevalência de $8 \%$ de obesidade nas escolas públicas e 30\% nas escolas privadas (Mello et al., 2004).

Estudo, realizado por Carvalho (2004) no município de Vinhedo - SP obteve um resultado de $20 \%$ de sobrepeso e obesidade nas escolas privadas e $14 \%$ de sobrepeso e $8 \%$ de obesidade em escolas públicas.

Pesquisa realizada por Balaban \& Silva, na cidade de Recife-PE com crianças e adolescentes em 1999, estimou sobrepeso na classe de renda alta em torno de $34,3 \%$ e obesidade em 15,1\%. Em contrapartida na classe de renda baixa obteve-se resultado na mesma ordem em torno de $8,7 \%$ e $4,4 \%$ respectivamente.

Em estudo de Arteaga et al. (1982), para avaliação de ocorrência de obesidade em 3 escolas de diferentes níveis sócio - econômicos realizada em Ribeirão Preto com estudantes de 7 a 12 anos encontrou prevalência para o nível sócio-econômico alto, médio e baixo de $38 \%, 12 \%$ e $4 \%$ respectivamente, similares aos nossos dados. 
Leão et.al (1982), na cidade de Salvador, observaram prevalência de 8\% de obesidade nas escolas públicas e 30\% nas escolas privadas, na mesma população (Lamonier, 2000)

Salles et.al.,(1999) avaliou obesidade em estudantes na faixa etária de 10 a 18 anos da rede pública e privada de ensino. Os dados encontrados demonstraram maior prevalência na rede pública com $13,1 \%$ em relação com a privada com 7,6\%.Esses dados diferem daqueles encontrados na presente pesquisa.

No mesmo sentido em 1992, Veiga et.al., realizaram avaliação nutricional em 192 adolescentes de uma escola de nível sócio- econômico alto e 102 alunos em 5 favelas de São Paulo ,SP. Encontraram 23\% de obesidade nas escolas de nível sócio econômico baixo e 18\% para as escolas de nível sócio - econômico alto (Lamonier, 2000).

Estudo bem recente realizado no Rio de Janeiro em escola pública e privada com adolescentes entre 11 e 15,9 anos, para avaliar o estado nutricional através do IMC e dobras cutâneas tricipital e subescapular, levando em consideração a maturação sexual revelou resultados de $6,6 \%$ de sobrepeso e $9,1 \%$ de obesos na escola pública e $9,0 \%$ e $18,1 \%$ nas escolas privadas respectivamente e o risco de apresentar sobrepeso/obesidade foi maior nos adolescentes em estágios mais avançados de maturação sexual, sendo que os estudantes da escola pública apresentaram processo de maturação sexual mais tardio do que os da escola privada (Oliveira \& Veiga, 2005).

Em nosso estudo nas escolas participantes encontrou-se maior prevalência de sobrepeso nas escolas privadas do que nas escolas públicas. Em relação à obesidade os dados encontrados foram de 3,8\% e 3,0 \% nas privadas e nas públicas respectivamente.

Addair ,Gordon \& Larsen (apud, Pozzobon, 2003) em estudo com 6507 meninas relacionaram a idade da menarca com a questão de sobrepeso, apontando que o sobrepeso foi mais significante em adolescentes com menarca precoce (surgimento do broto mamário antes dos 8 anos) onde as chances de meninas apresentarem sobrepeso quase duplicaram. 
Segundo Pozzobon (2003) na cidade de Xanxerê - SC ao comparar o percentual de gordura dos meninos e meninas com idade entre 11 e 13 anos segundo maturação sexual verificou-se que o grupo de maturados apresentou valor superior em relação ao grupo não maturado. Em meninas maturadas, neste mesmo estudo, a estatura apresentou-se superior quando comparada à de meninas não-maturadas da mesma idade. Estes valores vêm de encontro ao descrito por Tanner (1963) apud Guedes \& Guedes (1997) que relata que o pico máximo de crescimento se dá alguns meses antes da ocorrência da menarca. Desta forma deduz-se que maturação precoce resulta em um pico de crescimento mais cedo.

Comparando estes dados aos resultados encontrados com o nosso estudo pode-se dizer que eles são similares, pois em relação à maturação sexual 49,2\% eram maturados e 50,8\% não maturados. A prevalência de sobrepeso foi de 70\%,para adolescentes maturados e quanto a prevalência de obesidade o percentual entre maturados e não maturados foram muito semelhantes.

Estudos longitudinais realizados nos Estados Unidos da América em 1997 e na Holanda em 1996 demonstraram forte relação da menarca precoce com aumento de IMC. Ainda, autoras como Laitinem et al., em 2001 mostraram que quanto menor a idade da menarca maior o IMC aos 14 anos (Santos, 2003).

A idade da menarca é utilizada em estudos nacionais, como indicador de maturação biológica das características sexuais femininas e a sua ocorrência, são notadas variações em desenvolvimento de massa corporal. Em muitos estudos demonstram-se incremento de adiposidade corporal significativo após este advento (Pozzobon, 2003).

Quanto à idade média de ocorrência de maturação sexual, Colli (1985) estudando a maturação sexual dos adolescentes na cidade de Santo André - SP observou que a maturação sexual geralmente ocorreu até 13 anos no sexo feminino com aparecimento de pelos axilares na idade mediana de 10,5 anos e menarca ao redor dos 12,5 anos. Em estudos variados, a 
menarca ocorre em idades distintas: 12,5 anos em Cuiabá (Pereira \& Veiga, 1998), 13 anos em Botucatu (Goldberg et al., 1996) e na Europa ocorre entre 12,9 e 13,4 anos (Elizondo, 1992).

Em nosso estudo a maturação sexual ocorreu em média aos 11,9 anos com mediana de 12 anos e desvio padrão de 1,00, para os dois sexos. A idade média de ocorrência de maturação em muitos estudos, em torno de 12 anos se deve a uma tendência secular observada nos países desenvolvidos e que também vem sendo observada naqueles em desenvolvimento provavelmente devido as melhorias nas condições sanitárias, alimentares e habitacionais (Santos, 2003).

Yong Wang (2002) em estudo que envolveu 1520 meninos e 1501 meninas com idade entre 8 e 14 anos observou que a prevalência de obesidade em meninas com maturação sexual mais precoce era de $34,4 \%$ e $23,2 \%$ não eram obesas e constatou que meninos acima do peso tendem a sair da puberdade depois que os de menores pesos. O oposto ocorre em relação ao peso e maturidade em garotas. Este mesmo autor verificou que meninos de maturidade precoce estavam $40 \%$ menos propensos a ser obesos. Já as meninas de maturação precoce tinham risco de $10 \%$ maior de serem obesas.

A maturação sexual deve ser considerada como um aspecto relevante na avaliação do desenvolvimento físico dos adolescentes em função do aumento de estatura, peso e desenvolvimento muscular e aumento de depósitos de gordura em meninas (Colli, 1985; Duarte, 1993).

Diante dos diferentes resultados, encontrados nas diversas pesquisas pode-se descrever que diferenças metodológicas quanto à seleção da amostra e o critério de avaliação do estado nutricional em muitas pesquisas dificultam a realização das comparações entre os estudos, existindo uma grande variação dos resultados provavelmente devido aos distintos métodos e parâmetros de avaliação do estado nutricional usado em cada estudo (Santos, 2003). 


\section{CONCLUSÃO}

$\mathrm{Na}$ amostra estudada, 182 adolescentes (47,2\%) eram do sexo masculino e 204 $(52,8 \%)$ eram do sexo feminino.

Quanto a rede de ensino 185 adolescentes (47,9\%) eram da rede privada e $201(52,1 \%)$ eram da rede pública.

Quanto a maturação sexual $190(49,2 \%)$ eram maturados e $196(50,8 \%)$ não maturados.

A maioria dos adolescentes $323(83,6 \%)$ eram eutróficos, 50(13,0\%) apresentaram sobrepeso e $13(3,4 \%)$ apresentaram obesidade de acordo com a classificação de Must.

A prevalência de sobrepeso foi de $14,8 \%$ para o sexo masculino e $11,3 \%$ para o sexo feminino.Quanto a obesidade $4,9 \%$ ocorreu no sexo masculino e $2,0 \%$ no sexo feminino ou seja mais que o dobro de prevalência para o sexo masculino.

Nas escolas privadas foi maior o percentual de sobrepeso e de obesidade do que nas públicas, 16,2\% sobrepeso nas privadas e 10,0\% nas públicas e 3,8\% de obesidade nas privadas e 3,0\% nas públicas, sem diferença estatisticamente significativa.

Em relação a maturação sexual ocorreu mais do que o dobro de sobrepeso entre os maturados(18,4\%) em relação a obesidade os dados foram semelhantes, sendo um pouco superior nos adolescentes não maturados.

De acordo com os resultados encontrados, percebeu-se alta prevalência de sobrepeso principalmente na rede de ensino privado, com maior predominância no sexo masculino e maiores percentuais de sobrepeso em adolescentes maturados. Isso faz crer que essa situação 
nutricional aumenta os riscos de ocorrência de obesidade, caso não haja mudanças nos hábitos de vida destes adolescentes.

\section{CONSIDERAÇÕES FINAIS}

Esse trabalho foi de fundamental importância para a minha vida pessoal e profissional, pois não existia até então, nenhum trabalho que proporcionava embasamento para esclarecimento da avaliação nutricional de adolescentes na cidade onde exerço minha atividade docente. $\mathrm{O}$ interesse no desenvolvimento deste tema partiu primeiramente da curiosidade, depois veio à certeza e o desejo de desenvolvê-lo, pois pela realização de leituras percebi que não existia um consenso nacional para avaliar o estado nutricional de adolescentes nos diferentes locais do país.

Existe falta de unanimidade nos critérios apontados na literatura para o diagnóstico da obesidade infantil e na adolescência, indicando a necessidade de estabelecer pontos de corte específicos para cada população - considerando a maturação sexual.

Devido às distintas metodologias quanto à seleção da amostra e o critério de avaliação do estado nutricional em muitas pesquisas depara-se com a dificuldade quanto a realização das comparações entre os estudos, existindo grande variação dos resultados devido aos diferentes parâmetros de avaliação do estado nutricional usados em cada estudo. Sendo assim, há necessidade do estabelecimento de metodologia adequada e validade nacionalmente específica para esta faixa etária.

Estudos de diagnóstico nutricional são relevantes para apontar adolescentes que precisam receber tratamento especializado, pois na vida adulta, o sucesso terapêutico é de resultados mais duvidosos. 
Concomitante a esta estratégia faz-se necessário o desenvolvimento de programas de prevenção ainda na infância e adolescência, onde é mais fácil estabelecer hábitos saudáveis, pois os indivíduos são mais receptivos aos programas de educação e saúde e desta forma, promovem também o envolvimento da família.

Poderiam ser recomendadas medidas para implementação de políticas públicas na área de educação e saúde, visando prevenir o aparecimento da obesidade, por meio de campanhas governamentais veiculadas pelos meios de comunicação. Deve-se também incluir no currículo do ensino fundamental e médio os conteúdos programáticos de nutrição, promoção de alimentação saudável e peso adequado, além de incremento da atividade física desde a préescola. Outra abordagem seria o envolvimento das empresas alimentícias que poderiam veicular nos rótulos das embalagens mensagens de alimentação equilibrada.

Diante do exposto, existe uma necessidade emergente do desenvolvimento de pesquisas sobre prevalência de excesso de peso em adolescentes além de campanhas educativas e atividades de diversas naturezas para que essa situação de grande incremento se estabilize ou que ocorra decréscimo, pois a obesidade sem diagnóstico e tratamento eficazes é uma das enfermidades crônicas não transmissíveis das mais graves na atualidade.

Necessita-se de estratégias de ampla abrangência que estimulem os jovens e seus familiares para a aquisição de bons hábitos alimentares, combate ao sedentarismo e consequentemente melhor qualidade de vida. 
ANEXO 1 -Quadro 2- População de alunos de escolas públicas-

\begin{tabular}{|c|c|}
\hline ESTABELECIMENTO & TOTAL DE ALUNOS DE $5^{\mathrm{a}}$ à $8^{\mathrm{a}}$ SÉRIE \\
\hline C.E Ana Vanda Bassara & 476 \\
\hline C.E Antonio Tupy Pinheiro & 500 \\
\hline C.E César Stange & 660 \\
\hline C.E Cristo Rei & 829 \\
\hline C.E Palmeirinha & 493 \\
\hline C.E D.Pedro I & 599 \\
\hline C.E Dulce Maschio & 639 \\
\hline Centro de Educação Prof.Fco.C.Martins & 395 \\
\hline C.E Leni Marlene Jacob & 748 \\
\hline C.E Liane Marta da Costa & 642 \\
\hline C.E Mahatma Gandhi & 537 \\
\hline C.E Manoel Ribas & 546 \\
\hline C.E Padre Chagas & 645 \\
\hline C.E Professor Amarílio & 365 \\
\hline C.E Pedro Carli & 826 \\
\hline C.E Rui Barbosa & 240 \\
\hline C.E Ruben Fleury da Rocha & 396 \\
\hline C.E Visconde de Guarapuava & 524 \\
\hline C.E Ver. Heitor Rocha Kramer & 489 \\
\hline C.E Bibiana Bittencourt & 219 \\
\hline E.E Maria de Jesus P. Guimarães & 323 \\
\hline E.E Newton Felipe Albach & 254 \\
\hline E.E Moacyr Júlio Silvestre & 347 \\
\hline Escola Municipal Domingos Sávio & 358 \\
\hline Escola Municipal P.de Amaral & 136 \\
\hline TOTAL & 12.186 \\
\hline
\end{tabular}

Fonte: Secretaria Municipal de Educação de Guarapuava-PR /2004

\section{ANEXO 2}

QUADRO 3. População de Alunos de Escolas Particulares

\begin{tabular}{|l|c|}
\hline ESTABELECIMENTO & TOTAL DE ALUNOS DE 5a à 8 ${ }^{\text {a SÉRIE }}$ \\
\hline Colégio Adventista - EIFM & 105 \\
\hline Colégio Aliança - EIFM & 315 \\
\hline Colégio Assunção de Nossa Senhora - EIFM & 78 \\
\hline
\end{tabular}



da cidade de Guarapuava -PR

\begin{tabular}{|l|c|} 
Colégio Campo Real - EM & 145 \\
\hline Colégio Imp. Dona Leopoldina - EIFMP & 114 \\
\hline Colégio Nossa Senhora de Belém & 129 \\
\hline TOTAL & 886 \\
\hline
\end{tabular}

Fonte:Secretária Municipal de Educação e Secretaria das Respectivas Escolas- Guarapuava- PR 12004 


\author{
ANEXO 3 \\ UNIVERSIDADE DE SÃO PAULO \\ ESCOLA DE ENFERMAGEM DE RIBEIRÃO PRETO \\ TELEFONE: 602-3391 TELEX (0166)354- FAX (016) 633-3271 \\ CEP: 14040-902 - RIBEIRÃO PRETO - SP - Brasil
}

EU, RAQUEL ROSALVA GATTI, aluna de Pós - Graduação da Escola de Enfermagem de Ribeirão Preto, da Universidade de São Paulo, nível Mestrado, sob orientação da Prof $^{a}$.Dra . Rosane Pilot Pessa Ribeiro, estou desenvolvendo pesquisa intitulada "Prevalência de excesso de peso em adolescentes em duas escolas públicas e duas escolas privadas da cidade de Guarapuava-PR-.

O objetivo da pesquisa é avaliar a prevalência de excesso de peso em adolescentes do município de Guarapuava. As atividades desenvolvidas serão algumas perguntas de identidade do aluno, e medidas antropométricas (peso e altura) para cálculo de Índice de Massa Corporal. Será enviado também um termo de consentimento para os pais ou responsáveis para a autorização da realização da pesquisa.

As informações registradas serão sigilosas, sendo utilizadas somente para a minha pesquisa.

Os resultados serão divulgados em eventos científicos e publicados em periódicos, mas os sujeitos se manterão no anonimato.

A coleta de dados será desenvolvida na escola, sem comprometer o rendimento do aluno.

$\mathrm{Eu}$, $\mathrm{RG} \mathrm{n}$ ,abaixo assinado

responsável pela Colégio ,autorizo a realização da

pesquisa em dias agendados na subseqüência, com alunos de quintas a oitavas séries.

1. A garantia de receber resposta a qualquer pergunta ou esclarecimento a dúvidas acerca dos procedimentos, riscos, benefícios e outros relacionados com a pesquisa.

2. A segurança de que será preservada a identidade e privacidade do entrevistado.

3. A garantia de que não haverá riscos e nem desconfortos, ou gastos de qualquer natureza.

Telefone para dúvidas: (042) 627-3676 ou (042) 6291444- Ramal 244 ou (042) 99644999 


\section{ANEXO 4}

TABELA 12: Distribuição de Alunos Sorteados em Escolas Públicas segundo as séries e gênero. Secretaria nas respectivas escolas. $/ 2004$

\begin{tabular}{|c|c|c|c|c|c|c|c|c|c|c|}
\hline \multirow{2}{*}{$\begin{array}{l}\text { Colégio Estadual Ana } \\
\text { Vanda Bassara }\end{array}$} & \multicolumn{2}{|c|}{$5^{\mathrm{a}}$ série $\mathrm{A}$} & \multicolumn{2}{|c|}{$6^{\mathrm{a}}$ série $\mathrm{C}$} & \multicolumn{2}{|c|}{$7^{\mathrm{a}}$ série $\mathrm{C}$} & \multicolumn{2}{|c|}{$8^{a}$ série $A$} & \multicolumn{2}{|c|}{ Total } \\
\hline & $\mathbf{F}$ & $\mathbf{M}$ & $\mathbf{F}$ & $\mathbf{M}$ & $\mathbf{F}$ & $\mathbf{M}$ & $\mathbf{F}$ & $\mathbf{M}$ & $\mathbf{F}$ & $\mathrm{M}$ \\
\hline & 14 & 18 & 19 & 18 & 20 & 17 & 19 & 17 & 72 & 70 \\
\hline Colégio Estadual & \multicolumn{2}{|c|}{$5^{\text {a }}$ série $B$} & \multicolumn{2}{|c|}{$6^{\mathrm{a}}$ série $\mathrm{C}$} & \multicolumn{2}{|c|}{$7^{a}$ série $A$} & \multicolumn{2}{|c|}{$8^{\mathrm{a}}$ série $\mathrm{B}$} & \multicolumn{2}{|c|}{ Total } \\
\hline & $\mathbf{F}$ & $\mathbf{M}$ & $\mathbf{F}$ & $\mathbf{M}$ & $\mathbf{F}$ & $\mathbf{M}$ & $\mathbf{F}$ & $\mathbf{M}$ & $\mathbf{F}$ & $\mathrm{M}$ \\
\hline & 14 & 22 & 19 & 21 & 18 & 20 & 18 & 18 & 69 & 81 \\
\hline TOTAL & 28 & 40 & 38 & 39 & 38 & 37 & 37 & 35 & \multicolumn{2}{|c|}{292} \\
\hline
\end{tabular}




\section{ANEXO 5}

TABELA 13: Distribuição de alunos sorteados nas escolas privadas, segundo série e gênero secretaria das respectivas escolas março/2004.

\begin{tabular}{|c|c|c|c|c|c|c|c|c|c|c|c|c|c|c|c|c|}
\hline \multirow[t]{2}{*}{ Colégio Adventista } & \multicolumn{2}{|c|}{$5^{a}$ série $A$} & \multicolumn{3}{|c|}{$6^{\mathrm{a}}$ série $\mathrm{A}$} & \multicolumn{3}{|c|}{$7^{\mathrm{a}}$ série $\mathrm{A}$} & \multicolumn{2}{|c|}{$8^{\mathrm{a}}$ série $\mathrm{A}$} & \multicolumn{2}{|c|}{ Total } & & & & \\
\hline & $\mathbf{F}$ & $\mathbf{M}$ & & & $\mathbf{M}$ & $\mathbf{F}$ & & & $\mathbf{F}$ & $\mathbf{M}$ & $\mathbf{F}$ & $\mathrm{M}$ & & & & \\
\hline & 12 & 15 & & & 10 & 10 & & & 15 & 8 & 49 & 50 & & & & \\
\hline \multirow[t]{3}{*}{ Colégio Aliança } & \multicolumn{2}{|c|}{$5^{a}$ série $B$} & \multicolumn{2}{|c|}{$\begin{array}{c}5^{\mathrm{a}} \text { série } \\
\mathrm{C}\end{array}$} & \multicolumn{2}{|c|}{$6^{a}$ série $A$} & \multicolumn{2}{|c|}{$6^{a}$ série $C$} & \multicolumn{2}{|c|}{$7^{a}$ série $A$} & \multicolumn{2}{|c|}{$7^{a}$ série $B$} & \multicolumn{2}{|c|}{$8^{a}$ série $A$} & \multicolumn{2}{|c|}{$8^{a}$ série $C$} \\
\hline & $\mathbf{F}$ & $\mathbf{M}$ & $\mathbf{F}$ & $\mathbf{M}$ & $\mathbf{F}$ & $\mathbf{M}$ & $\mathbf{F}$ & $\mathbf{M}$ & $\mathbf{F}$ & $\mathbf{M}$ & $\mathbf{F}$ & $\mathbf{M}$ & $\mathbf{F}$ & $\mathbf{M}$ & $\mathbf{F}$ & $\mathbf{M}$ \\
\hline & 9 & 11 & 6 & 13 & 9 & 15 & 9 & 13 & 11 & 19 & 10 & 17 & 13 & 9 & 12 & 10 \\
\hline Total duas escolas & & & & & & & & & & & & & & & & \\
\hline
\end{tabular}

Fonte: Secretaria das respectivas escolas março/2004

$\mathrm{F}$ - sexo feminino

$\mathrm{M}$ - sexo masculino 


\title{
ANEXO 6
}

\section{UNIVERSIDADE DE SÃO PAULO \\ ESCOLA DE ENFERMAGEM DE RIBEIRÃO PRETO \\ TELEFONE: 602-3391 - TELEX (0166) 354 - FAX ( 016)633-3271 OU 630-2561 \\ MESTRADO INTERINSTITUCIONAL - USP - UNICENTRO \\ UNICENTRO - UNIVERSIDADE ESTADUAL DO CENTRO - OESTE}

\author{
TERMO DE CONSENTIMENTO LIVRE E ESCLARECIDO
}

EU, RAQUEL ROSALVA GATTI, professora do Curso de Nutrição da UNICENTRO Guarapuava - PR e aluna da Pós-Graduação da Escola de Enfermagem de Ribeirão Preto da Universidade de São Paulo, nível mestrado, sob orientação da profa. Dra ${ }^{a}$. Rosane Pilot Pessa Ribeiro, estou desenvolvendo pesquisa intitulada "Prevalência do excesso de peso em adolescentes em duas escolas públicas e duas escolas privadas da cidade de Guarapuava - PR".

O objetivo da pesquisa é verificar a prevalência do excesso de peso em adolescentes de escolas públicas e privadas da cidade de Guarapuava. Para tal é necessário realizar uma coleta de dados, relativos a medidas de peso e altura dos adolescentes. A coleta de dados será realizada na escola, sem comprometer o rendimento do aluno, sendo que a mesma foi autorizada pela diretora da escola onde seu filho estuda.

$\mathrm{Eu}$, RG $n$

abaixo assinado responsável pelo adolescente que será medido e pesado, confirmo ter recebido as informações sobre a pesquisa a ser desenvolvida, e ciente dos direitos abaixo relacionados, autorizo sua participação, sabendo que é assegurada a preservação da identidade e privacidade do entrevistado. E recebo também:

$>$ Garantia de receber resposta a qualquer pergunta ou esclarecimento a dúvidas acerca dos procedimentos, e outros relacionados à pesquisa..

$>$ A segurança que será preservada a identidade e a privacidade do entrevistado.

$>$ A garantia de que não haverá riscos, desconforto e nem gastos de qualquer natureza.

Telefone para dúvidas ou contato com o pesquisador (42) 627- 3676 ou (42) 629-1444 Ramal 244.

Participante da pesquisa

Raquel R. Gatti

Pais/responsáveis 
ANEXO 7

INSTRUMENTO PARA COLETA DE DADOS

\section{IDENTIFICAÇÃO}

Escola Série

Nome do aluno

Data de nascimento:

Sexo masculino ( ) Sexo feminino ( )

\section{DADOS ANTROPOMÉTICOS:}

Peso:

Altura:

IMC:

\section{MATURAÇÃO SEXUAL:}

Presença da menarca para o sexo feminino ( )Sim ( )Não.Caso a resposta seja afirmativa, com que idade menstruou? anos.

Presença de pelos axilares, para o sexo masculino ( )Sim ( )Não.Caso a resposta seja afirmativa, em que idade houve aparecimento dos pelos? anos. 


\section{REFERÊNCIAS}

ABRAHÃO,C.A.Obesidade.Disponívelem:http://www.sitemédico.com.br/artigos_sp/obesida de.asp. Acesso em: 12 jun. 2002.

ABERASTURY, A.; KNOBEL, M. Adolescência normal. Porto Alegre: 1981.

ABRAnTES, M. M.; LAMOUNIER, J. A.; COLOSIMO, E. A. Prevalência de sobrepeso e obesidade em crianças e adolescentes das regiões Sudeste e Nordeste. Jornal de Pediatria, Rio de Janeiro, v. 78, n. 4, 2002.

ALBANO, R. D.; SOUZA, S. B. Estado nutricional de adolescentes: "risco de sobrepeso"e “sobrepeso" em uma escola pública do Município de São Paulo. Caderno de Saúde Pública, Rio de Janeiro, v. 17, n. 4, p. 941, jul./ago. 2001.

ALMEIDA, A. P. C.; COSTA, L. C.; GOMES, R. N. Prevalência de obesidade e sobrepeso em estudantes de diferentes classes sociais. In: SIMPÓSIO OBESIDADE E ANEMIA CARENCIAL NA ADOLESCÊNCIA, 2000, Salvador. Anais. São Paulo: Instituto Danone, 2000. p. ALMEIDA, F. N; ROUQUAYROL, M. Z. Introdução à epidemiologia. Rio de Janeiro. Medsi, 2002.

ANJOS, L. A. Índice de massa corporal (massa corporal / estatura ${ }^{2}$ ) como indicador do estado nutricional de adultos: revisão da literatura. Rev Saúde Públ, v. 26, p. 431-436, 1992.

ANJOS, L. A. O índice de massa corporal só deve ser usado em indivíduos com mais de 20 anos de idade. In: SIMPÓSIO INTERNACIONAL DE CIÊNCIAS DO ESPORTE, 19., 1994, São Caetano do Sul. Anais. São Caetano do Sul: CELAFISCS, 1994. p. 194. 
ANJOS, L. A.; VEIGA, G. V.; CASTRO, J. R. R. Distribuição dos valores do índice de massa corporal da população brasileira até 25 anos de idade. Revista Panamericana de Salud Pública, v. 3, p. 164-173, 1998.

ARTEAGA, H. P.; SANTOS, J. E.; DUTRA DE OLIVEIRA, J. E. Obesity among schoolchildren of different socioeconomic levels in developing country. International Journal of Obesity, 6, 291-297, 1982.

BALABAN, G.; SILVA, G. A. P. Prevalência de sobrepeso e obesidade em adolescentes de uma escola de classe médio-alta de Recife-PE. In: SIMPÓSIO OBESIDADE E ANEMIA CARENCIAL NA ADOLESCÊNCIA, 2000, Salvador. Anais. São Paulo: Instituto Danone, 2000. p. 217.

BARBOSA, M. E. R. Crescimento e desenvolvimento na adolescência. Disponível em: $<$ http//www.dianet.hpg.com.br/ncrescimento.htm>. Acesso em: 03 fev. 2004.

BELLIZZI, M. C.; DALLAL, G. E.; DIETZ, W. H. Reference data for obesity $85^{\text {th }}$ and $95^{\text {th }}$ percentiles of body mass index $\left(\mathrm{wt}^{\mathrm{h}} / \mathrm{ht}^{2}\right)$ a corretion. Am. J. Clin Nutrition, v. 54, p. 773, 1991.

BERGADA, C. A puberdade e a medicina do adolescente. Anais Nestlé, São Paulo, v. 55, p.1-8, 1998. in: Revista de Nutrição - v 14- Campinas 2001.

BIANCULLI, C. H. Crescimento físico y endocrinologia en la pubertad. In: ORGANIZACIÓN PANAMERICANA DE LA SALUD. La salud del adolescente y del joven. Washington: OPAS, 1995. p. 87-94.

BORGES, J. B. R; GUARISI, J.; GIATTI, M. J.G.; BASTOS, A.C. Obesidade e hipercolesterolemia na adolescencia. Revista de Ginecologia \& Obstetricia, São Paulo n. 2, 2000 . 
BRASIL. Ministério da Saúde. Instituto Nacional de Alimentação e Nutrição (INAN). Perfil de crescimento da população brasileira de 0 a 25 anos: Pesquisa Nacional sobre Saúde e Nutrição. Brasília: INAN, 1990.

BRASIL. Ministério da Saúde. Normas de atenção à saúde integral do adolescente. Brasília: Ministério da Saúde, 1993.

BRASIL. Ministério da Saúde. Secretaria de Políticas da Saúde. Saúde e desenvolvimento da juventude brasileira: construindo uma agenda nacional. Brasília: Ministério da Saúde, 1999. $22 \mathrm{p}$.

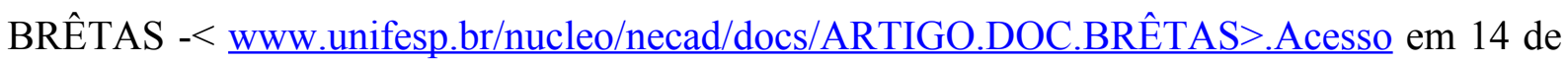
out.2003.

BRIDGMAN, C. L. Some special problems in abnormal adolescent psychology, Med Press, v. 106, p.118-22, 1918.

BUENO, A. L.; MELLO, E. D. Revisão Literária e Análise Crítica de Curvas de Crescimento. Rev Nutrição e Pediatria, , p. 33-37, nov. /dez. 2004.

CAMARA, F. P. Glossário de epidemiologia e ecologia das doenças infecciosas e parasitárias. Disponível em: http://www.microbiologia.ufrj.br/ . Acesso em: 24 agosto 2005.

CHAUl, D. N.; CUNHA, I. C.; MATTOS, L. C.; MELO, N. C. S. PEREIRA, C. V; HADLER, M. C. C. M. Antropometria e alimentação de adolescentes, no município de Goiânia In: SIMPÓSIO OBESIDADE E ANEMIA CARENCIAL NA ADOLESCÊNCIA, 2000, Salvador. Anais. São Paulo: Instituto Danone, 2000. p. 215-216. 
CASTILHO, M. Saúde da criança e do adolescente: Composição Corporal durante o processo de maturação sexual em adolescentes de ambos os sexos. Disponível em:

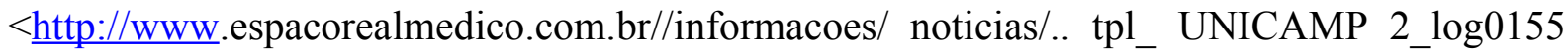
sht> Acesso em: 03 fev. 2004.

CARVALHO, M. Prevalência de sobrepeso e obesidade em escolas públicas e privadas da cidade de Vinhedo-SP: Alimentando a educação. In: SEMINÁRIO DE ALIMENTAÇÃO ESCOLAR, 4., 2004., São Paulo: 2004. p.

CARRASCOSA, A.; GUSSINYÉ, M. Crescimento e mineralização do esqueleto durante a puberdade e a adolescência: regulação nutricional e hormonal. Anais Nestlé,São Paulo, v. 55, p. 9-17, 1998.

CHIARA, V.; SICHIERI, R.; MARTINS, P. D. Sensibilidade e especificidade de classificação de sobrepeso em adolescentes. Revista Saúde Pública, Rio de Janeiro, v. 37, n. 2, p. $226-31,2003$.

CHIPKEVITCH, E. Puberdade \& Adolescência: Aspectos Biológicos, Clínicos e Psicossociais. São Paulo: Rocca, 1995. p. $06-49$.

CINTRA, I. P; COSTA R. F.; FISBERG, M. Atualização em obesidade na infância e adolescência. São Paulo: Atheneu, 2004. p. 32-39.

COLLI, A. S. Maduración sexual de los adolescentes de São Paulo. In: ORGANIZACIÓN PANAMERICANA DE LA SALUD. La salud del adolescent y joven en las ameritas. Washington: OPASS, 1985. p. 249-58. (Publicación científica 4890).

COLLI, A. S. Maturação sexual na população brasileira: limites de idade. Jornal de Pediatria, Rio de Janeiro, v. 60, n. 4, p. 173-175, 1986. 
COLLI, A. S. Monitorização do crescimento e desenvolvimento físico. In : COATES, V.; FRANÇOSO, L. A.; BEZNOS, G. W. Medicina do Adolescente. São Paulo: Savier, 1993. p. $51-56$.

COUTINHO, W. Convenção Latino Americana para consenso da obesidade. Rio de Janeiro: EDITORA, 1998. 116 p.

DAMIANI, D.; CARVALHO, D. P. de; OLIVEIRA, R. G. Obesidade na infância - um grande desafio! Revista Pediatria Moderna, São Paulo, v. 36, n. 8, p.489-528, ago. 2000.

DAMIANI, D.; CARVALHO, D. P. de; OLIVEIRA, R. G. Obesidade: fatores genéticos ou ambientais. Revista Pediatria Moderna, São Paulo, v. 28, n. 8, p 23-25, mar. 2002.

DE ANGELIS, R. Desafios para vencer a obesidade. Nutrição em Pauta, São Paulo, v.10, jan./fev. 2002.

DIETZ, W. H. Critical periods in childhood for the development of obesity. American Journal of clinical Nutrition, , v. 59, p. 955-959, 1994.

DORFMAN, I.; GREULICH, W. W; SOLOMON, C. I. The excretion of androgenic and estrogenic substances in the urine of children. Endocrinology, , v. 21, p. 130-132, 1937.

DUARTE, M. F. S. Maturação física: uma revisão da literatura, com especial atenção à criança brasileira. Cad. Saúde Pública, , v. 9 (supl. 1), p. 71-84, 1993.

ECKERT, H. M. Desenvolvimento motor. São Paulo: MANOLE, 1993.

ELIZONDO, S. Age at menarche : its relation to linear and ponderal growth. Am. Hum. Biol., , v. 19, p. 197-199, 1992. 
FISBERG, M. Obesidade na infância e adolescência. São Paulo: Fundação BYK, 1995. 157 p.

FONSECA, V. M; SICHIERI, R.; VEIGA, G. V. Fatores associados a obesidade em adolescentes. Revista de Saúde Pública, São Paulo, v.32, n.6, dez. 1998.

FORATTINI, O. P. Epidemiologia geral. São Paulo: Editora Edgard Blücher Ltda., 1976, p. 132.

FORBES, G. B.; KING, J. C. Nutritional concerns during adolescent. Pediatr. Clin. North. Am., , v. 27, p. 125-139, 1987.

OBESIDADE já é quase tão letal quanto o fumo. Folha de São Paulo, São Paulo, 10 mar. 2004. Capa Mundo.

FREDERICO, P. C; VITAlle, M. S. S; SARDINHA, F. A. A; AMANCIO, O. M. S. Perfil do desenvolvimento puberal e do estado nutricional de adolescentes. Revista Paulista de Pediatria, São Paulo, v.15, n. 1, p. 31-35, março 1997.

FRISANCHO, A. R. Anthropometric standards for the assesment of growth and nutritional status Ann Arbor._Michigan, EUA: The University of Michigan Press, 1990.

FULLER, F. M. Adolecence, its relation to primary and secondary disease. J Iowa State M Soc, , v. 4, p. 369-374, 1914-5.

GARROW, J. S.; WEBSTER, J. Quelet' s index (W/H) as mesure of fatness. International Journal of Obesity, , v. 9, p. 147-153, 1985. 
GRAY, G. E.; GRAY, L. K. Anthropometric measurements and their interpretation: principles, practices and problems. J Am Diet Assoc., v. 77, n. 5, p. 534-539, 1980.

GALlAGHER, J. R. A clinical for adolescents. Children, v. 1, p. 165, 1954.

GARCIA, G. C. B.; GAMBARDELLA, A. M. D.; FRUTUOSO, M. F. P. Estado nutricional e consumo alimentar de adolescentes de um centro de juventude da cidade de São Paulo. Revista de Nutrição, Campinas, v. 16, n. 1, p. 41-50., jan./mar., 2003.

GAMBARDELlA, M. D.; FRUTUOSO, M. F. P.; JULIANO, B. A. Anemia em adolescentes segundo maturação sexual. Revista de Nutrição, Campinas, v. 17, n. 1, p. 37-43, jan./mar. 2004.

GARN, S. M.; BAILEY, S. M. ; SOLOMON, M. A. ; HOPKINS. Effect of remaining family members of fatness prediction. Pediatrics Rev., v. 3, p. 148-153, 1991.

GASPARINI, S. Obesidade na infância e adolescência. Disponível em: $<$ http//server.nib.unicamp.br/sval/artobes.html> Acesso em: 14 jul. 2003.

GATES, A. E. The work of the adolescente clinic of Stanford University Medical Schoool. Arch Pediatr, v. 35, p. 236-43, 1918.

GUTHRIE, H. A.; PICCIANO, M. F.; SCOTT, A. Nutrition from childhood through adolescente. In: Human Nutrition. Missouri: Mosby -Year Book, 1995.

GOLDBERG, T. B. L.; COLLI, A. S.; CURI, P. R. Relação entre área do braço, área do músculo, área de gordura do braço e a menarca em adolescentes do município de Botucatu. J Pediatr, Rio de Janeiro, v. 72, p. 85-92, 1996. 
GUEDES, D. P.; GUEDES, J. E. R. P. Crescimento, composição corporal e desempenho motor em crianças e adolescentes. São Paulo: CLR Baliero, 1997. p. 362.

HALPERN, Z. S. C. et al. Treatment of obesity in children: special cases. Intern. J. of Obesity, LOCAL, n. 19, p. 273-114, 1995.

HAMMER, L. D. The development of eating, belavior in childhood. Ped.Clin. North Am, , v. 39, n. 3, p. 779-394, 1992.

HEALD, E. P. Adolescent nutrition. Med Clin Nort. Am., v. 59, n. 6, p. 1329-336, 1975.

HEALD, F. P. History of adolescent medicine. In: McANRNEY, E.; KREIPE, R. E.; ORR, D. P.; COMERCI, G. D.(Ed). Textbook of adolescent medicine. Philadelphia: WB Saunders, 1992.

HIMES, J. H.; DIETZ, W. H. Guidelines for overweight in adolescent preventive services. Recomendations from na expert committee. The expert committee on clinical guidelines for overweight in adolescente prevention. Services. American Journal of clinical nutrition, , v. 59, p. 307-316, 1994.

IBGE. Ministério do Planejamento, Orçamento e Gestão. Pesquisa de Orçamentos Familiares 2002/2003. Análise da disponibilidade domiciliar de alimentos e do estado nutricional no Brasil. Rio de Janeiro, 2004.

INSTITUTO DE ENDOCRINOLIGIA E NUTRIÇÃO. Índice de crianças e adolescentes obesos saltou 240\% no Brasil. Disponível em: <www.drien.com.br/ ien>. Acesso em: 04 out. 2004.

JACOBSON, M. S. Nutrição na adolescência. Anais Nestlé, São Paulo, v. 55, p. 25, 1998. 
JASTROW, J. The natural history of adolescence. Popular Science Monthly, v. 66, p. 45765, 1905.

JUliano, B. A; FRUTUOSO, M. F. P; GAMBARDEllA, A. M. D. Anemia em adolescentes segundo maturação sexual. Rev. de Nutrição, Campinas, v.17, n.1, p.37-43, jan./mar.2004

KREIPE, R. E. Normal somatic adolescente growth and development. In: McANRNEY, E. R.. Textbook of Adolescente Medicine. Philadelphia: [s.n.], 1992. p. 44-46.

LAMONIER, J. A. Situação da obesidade no Brasil. In:. SIMPÓSIO OBESIDADE E ANEMIA CARENCIAL NA ADOLESCÊNCIA, 2000, Salvador. Anais. São Paulo: Instituto Danone, 2000. p. 270.

LEAL, M. M.; SILVA, L. E.V. Crescimento e desenvolvimento puberal. In: SAITO, M. I..; SILVA, L. E. V. (Coord.) Adolescência : prevenção e risco. São Paulo: Atheneu, 2001. p. 4157.

LIMA REIS, J. P. Obesidade na infância e adolescência: Experiência em Portugal. Comunicação Pessoal no Curso de Atualização em Nutrição Pediátrica, 1998, Salvador. Anais. São Paulo: Instituto Danone, 2000. p.

LIMA, ARRAISLL \& PEDROSA. Rev. Nutrição, Campinas, v. 17, n. 4, out./dec. 2004.

MALINA, R. M. Adolescent growth and maturation: selected aspects of current research. Yearb Phys Anthropol, v. 21, p. 63, 1978.

MALLINA, M. M.; KTZMARZYK, P. T. Validity of the body index as an indicator of the risk and presence of overweight in adolescents. Am J Clin Nutr., v. 70, Suppl 1, p. 131-136, 1999. 
MAPES, C. C. The ethics of adolescence. Urology and cutaneous Rewiew, v. 21, p. 130$132,1917$.

MARINO, D. D.; KING, J. C. Nutritional concerns during adolescence. Pediatr Clin. North Am, v. 27, p. 125-139, 1980.

MARTORELL A. A obesidade em crianças de países em desenvolvimento: um problema de Saúde Pública? Nestlé Nutrition Workshop Series. Programa Pediátrico, v. 47, p. 50-52, 2000 .

MARTHA, P. M. Jr.; GORMAN, K. M.; BLIZZARD, R. M. et al. Endogenous growth hormone secretion and clearance rates in normal boy, as determined by deconvolution analysis: relationship to age, pubertal atatus, and body mass. J Clin Endocrinol Metab, v. 74, p. 336-44, 1992.

MELLO, E. D; LUFT, V. C; MEYER, F. Obesidade infantil: como podemos ser eficazes? Jornal de Pediatria, Rio de Janeiro, v. 80, n. 3, p. 73-82, 2004.

MINISTÉRIO DA SAÚDE. Normas de atenção à saúde integral do adolescente. Brasília, 1993.

MONTEIRO, C. A; MONDINI, L.; SOUZA, A. L. M.; POPKIN, B. M. Da desnutrição para a obesidade: a transição nutricional no Brasil. In: MONTEIRO, C. A. Velhos e novos males da saúde no Brasil: a evolução do país e suas doenças. São Paulo: Hucitec, 1995. p. 24755.

MULlER, R. C. Obesidade na adolescência.: Disponível em: $<$ http://www.cibersaude.com.br.revista.asp?id-materia=1413\&fase $>$ Acesso em: 28 jun. 2002. 
MUST, A; DALLAL, G.E; DIETZ, W.H. Reference data for obesity: 85 th and 95 th percentiles. Of body mass index. American Journal of Clinical Nutrition, v. 53, p. 839846, 1991.

MUST, A.; JACQUES, P. F.; DALLAL, G. E. et al. Long-term morbility and mortality of overweight adolescents: a follow up of the 1922-35.Harvard Growth Study. N Engl J Méd., v.327, p1350 -1355, 1992.

NOLASCO, M. P. B. Estudos dos fatores de risco, composição corporal e valores de lipídios e lipoproteínas em crianças obesas. São Paulo: EPM/ UNIFESP, 1992 . (Tesedoutorado).

NOVAES, J. F; BORGES, A. E. B; PRIORE, S. E; FRANCESCHINI, S. C. C. Fatores associados à obesidade na infância e adolescência. Revista Nutrição Brasil, v. 2, n. 1, jan./fev. 2003.

NUNES, A. M. A.; ABUCHAIM, A. L. G. Transtornos alimentares e obesidade. Porto Alegre: Art. Méd, 1998.

OCHSENHOFER, K.; FIORE, E. G.; COSTA, E. C. Avaliação do estado nutricional de crianças e adolescentes institucionalizados. Nutrição em Pauta, São Paulo, v. 12, n. 65, p. 22-27, mar./abr., 2004.

OLIVEIRA, J. Terapias não tradicionais na Obesidade. Abeso, São Paulo, n. 6, p. 7, 2002.

OLIVEIRA, C. L.; MELlO, M. T.; CINTRA, I. P.; FISBERG, M. Obesidade e síndrome metabólica na infância e adolescência. Rev. Nutr., Campinas, v. 17, n. 2, p. 237-245, abr./jun. 2004. 
OLIVEIRA, E. A. J. Estado Nutricional no Estirão Pubertário. Disponível em:

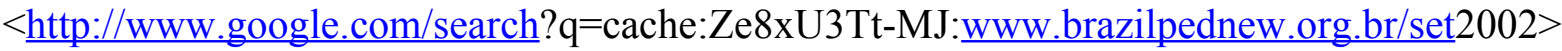
Acesso em: 02 jun. 2004.

OLIVEIRA, C. L; FISBERG, M. Obesidade na Infância e adolescência: uma verdadeira epidemia. Arq. Bras. Endocrinol.Metab., São Paulo, v. 47, n. 2, abr. 2003.

OLIVERIA, C. S.; VEIGA, G. V. Estado nutricional e maturação sexual de adolescentes de uma escola pública e de uma escola privada do Município do Rio de Janeiro. Revista Nutrição, Campinas, v.18, n. 2, p. 183-191, março/abril 2005.

ORGANIZAÇÃO MUNDIAL DA SAÚDE. FNUAP. UNICEF. Saúde reprodutiva de adolescentes: uma estratégia para a ação. Genebra: OMS, 1989. 21 p.

ORGANIZAÇÃO MUNDIAL DA SAÚDE. Overweight adults. In: Psysical status: the use and interpretation of antropometry. WHO Technical Report, Séries 854, Genebra, 1995.

OSÓRIO, L. C. Adolescente hoje. Porto Alegre: Artes Médicas, 1989. 103 p.

PENÃ, M.; BACALLAO, J. La obesidad en la pobreza: Un nuevo reto para la salud pública. Washington, D.C: OPS, 2000. (Publicação científica n. 576)

PEREIRA, S. F.; VEIGA, G. V. Avaliação nutricional de adolescentes. Perfil nutricional de adolescentes de baixa renda: indicadores antropométricos e de maturação sexual. Pediatria Moderna, v. 34, n. 6, p. $279-290,1998$.

PRIORE, S. E. Composição corporal e hábitos alimentares de adolescentes: uma contribuição à interpretação de indicadores nutricionais. Tese (Doutorado). São Paulo: Universidade Federal de São Paulo, 1998. 
POZZOBON, M. E. Crescimento, composição corporal e aptidão física de meninas maturadas e não maturadas sexualmente. Revista Digital, Buenos Aires, v. 9, n 64, 2003.

RAMOS, A. M. P. P.; BARROS FILHO, A. A. Prevalência da obesidade em Adolescentes de Bragança Paulista e sua relação com a obesidade dos pais. Arquivo Bras. Endocrinol. Metab., Campinas, v. 47, dez. 2003.

RAMOS, F. R. S.; PEREIRA, S. M; ROCHA, C. R. M. Viver e adolescer com qualidade. In: RAMOS, F. R. S; MONTICELli, M.; NITSCHKE, R.G (Org). Projeto Acolher: um encontro da enfermagem com o adolescente brasileiro. Brasília (DF): ABEN/MS, 2001. p.19-32.

ROCHE, A. F.; SIERVOGEL, F. M.; CHUMLEA, W. C.; WEBB, P. Grading body fatness from limited anthropometric data. A. M. J. Clin. Nutr., v. 34, p. 2831-2838, 1981.

RODRIGUEZ-GARCIA, R.; RUSSEL, J. S.; MADDALENO, M.; KASTRINAKIS, M. EI ambiente Legislativo y de Políticas relacionado com la Salud del Adolescente em América Latina y el Caribe. Washington, DC: OPS, 1999. 162 p.

ROSE, S. R.; KIBARIAN, M.; GELATO, M. et al. Sex steroids increase spontaneous growth hormone secretion in short children. J .Pediatr Endocrinol, , v. 3, p. 1-6, 1988.

ROSENBAUM, M.; LEIBEL, R. L. Obesity in childhood . Pediat Rev,. 11, p. 43-55. 1989.

ROOT, N. A; POWERS, P. S. Anorexia nervosa presenting as growth retardation in adolescente. J Adolescent Health Care, p 59-65, 1983.

SAITO, M. I. Aceleração e desaceleração do crescimento. In: COATES, V.; FRANÇOSO, L. A.; BEZNOS, G. W. Medicina do adolescente. São Paulo: Savier, 1993. 
SAITO, M. I. Medicina de Adolescentes: visão histórica e perspectiva atual. In: SAITO, M. I;

SILVA, L. E. V. (Coord.) Adolescência: prevenção e risco. São Paulo: Atheneu, 2001. p. 39 .

SAMPEI, M. A.; RIBEIRO, L. C.; DEVINCENZI, M. U.; SIGULEM, D. M. Adolescência: Estado Nutricional, práticas e distúrbios alimentares e atividade física. Rev. Compacta,. Disponível em: < http://www.pnut.epm.br/dowlonand> Acesso em: 17 set. 2004.

SANTOS, G. V. B. dos. Excesso de peso e seus fatores de risco em adolescentes da rede pública e privada de ensino no município de Ribeirão Preto SP - Brasil. Ribeirão Preto, 2003. Tese (Doutorado) - Curso de pós-graduação da Escola de Enfermagem de Ribeirão Preto da Universidade de São Paulo.

SATYANARAYANA, K.; KRISHNA, T. P.; RAO, B. S. N. Effect of early childhood undernutrition and child labour on growth and nutritional status of rural. Indian boys around. Hy debord. Hum. Nun. Clin. Nutri, , v. 40, n. 2, p. 131-139, 1986.

SICHIERI, R; ALLAM, V. C. Avaliação do estado nutricional de adolescentes brasileiros através do índice de massa corporal. Jornal de Pediatria: Associação Brasileira de Pediatria, , v. 72, n. 2, p. 80-84, 1996.

SICHIERI, R. Epidemiologia da obesidade. Rio de Janeiro: Ed. UERJ, 1998. 140 p. (Coleção Saúde \& Sociedade).

SIGULEM, D.M; TADDEI, J.A.A.C; ESCRIVÃO, M.A.M.S; DEVINCENZI, M.U. Obesidade na infância e adolescência. Compacta Nutrição, São Paulo, v. 2, n. 1, jun./ 2001.

SILEO, E. Evaluación clínica del dasarrollo puberal. In: OPAS. La Salud del adolescente y el joven en las Américas. Organizacion Panamericana de la salud, 1985. (Publicação Científica n. 489). 
SILVA, M. C. M.. Epidemiologia da obesidade. Jornal do Conselho Federal de Nutricionistas, São Paulo, p. 6-8, dez. 1998.

SILVA, R. A. R. N. Deficiência marginal de vitamina A em recém-nascidos, puérperas e préescolares atendidos na rede pública de Saúde do Município do Rio de Janeiro. Tese de doutoramento. Escola Nacional de Saúde Pública. Rio de Janeiro, 1998.

Site do Centers for Disease Control and Prevention (CDC): $\underline{\text { http://www.cdc.gov/growtcharts/ }}$ acesso 22/05/05.

Sotello, Y. O. M; COlugnati, F. A. B; TADDEI, J. A. A. C. Caderno de Saúde Pública, Rio de Janeiro, v. 20, n. 1, 2004.

TANNER, J. M. Growth at adolescence. Oxford: Blackwell Scientific publications, 1963.

TORRES, I.; CORREIA, F.; CRUZ, C.; MAIA, J.; LIMA REIS, I. P. Prevalência da obesidade. Arquivos de Medicina, LOCAL, v. 3, p. 377, 1990.

UBEDA, E. M. I. Programa de Atendimento à Saúde do Adolescente: a percepção dos atores sociais envolvidos. Ribeirão Preto, 1996. Tese (Doutorado) - Escola de Enfermagem, Universidade de São Paulo, Ribeirão Preto.

US DEPARTAMENT OF HEALTH AND HUMAN SERVICES. Physical activity and health; c report of the Surgeon General. Atlanta, Georgia: US Departament of health and human service, Center for Diseases Control, National Center for Chronic. Disease Prevention and health promotion, 1996. 
US DEPT HEALTH HUMAN SERVICES. Am Sh Health Associ Adv Health Assoc, Soc Public Health Educ Inc.The National Adolescence Student Health Survey: A report of the Health of America"s Youth. Oakland: Third Party, 1989.

VITALlE, M. S. S.; AMANCIO, O. M. S. Perfil do desenvolvimento puberal e do estado nutricional de adolescentes. Rev. Paulista Pediatria, São Paulo, v. 15, n. 01, p. 31, mar. 1997.

WALTRICK, A. C. A.; DUARTE, M. F. S. Estudo das características antropométricas de 7 a 17 anos: uma abordagem longitudinal mista e transversal. Revista Brasileira de Cineantropometria \& Desempenho Humano, v. 2, n. 1, p. 17-30, 2000.

WINNICOTT, D. W. A família e o desenvolvimento individual. São Paulo: Martins Fontes, 1993. In: Revista brasileira de psiquiatria.v.36,n 4 -2002.

World Health Organization. Consultation on obesity. Obesity: Prevantiong and managing the global epidemic. Geneva, Switzerland: WHO, 1997.

WORLD HEALTH ORGANIZATION. Psysical status: the use and interpretation of anthropometry. Geneva: WHO, 1995. (Technical Report Series 854)

$\leq$ www.sitemedico.com.br/artigos/cabrahao sp/obesidade.asp $>$ Acesso em: 12 ago. 2002

WANG, Y. Obesidade e maturação sexual. Pediatrics, v. 110, n. 5, p. 903-10, nov. 2002. 